\title{
CONTRIBUCIÓN AL ARTE RUPESTRE LEVANTINO: ANÁLISIS ETNOGRÁFICO DE LAS FIGURAS ANTROPOMORFAS *
}

\author{
MARÍA FRANCIA GALIANA \\ Universidad de Alicante
}

A mis padres

\begin{abstract}
El propósito del presente artículo es aplicar la lectura etnográfica a las figuraciones humanas representadas en el Arte Rupestre Levantino. Ello permite realizar una tipología de los adornos y útiles, así como aproximarse a su cronología relativa mediante los paralelos, muebles y figurativos, y las asociaciones de estos objetos en una misma figura. El resultado hace posible el acercamiento al encuadre cronológico-cultural de los pintores levantinos.

Le but que nous poursuivons c'est appliquer la lecture éthnographique aux figurations humaines représentées dans l'Art Rupestre Levantin. Ceci nous permet d'effectuer une tipologie des parures et de l'outillage, de même que nous approcher à leur chronologie relative moyennant les parallèles, avec le mobilier archéologique et d'autres représentations artistiques, ainsi que les associations de ces objets sur un même personnage. Le résultat rend possible l'aproximation au cadre chronologique-culturel des peintres levantins.
\end{abstract}

\section{INTRODUCCIÓN}

La aplicación de la lectura etnográfica al Arte Rupestre Levantino se revela de gran interés puesto que el análisis de las representaciones de objetos (útiles, adornos e indumentarias), confrontados con paralelos muebles y figurativos, tanto peninsulares como extrapeninsulares, permite una aproximación al encuadre cronológico-cultural de sus autores. Esta línea de investigación fue iniciada por Wernert (1917) y, posteriormente, retomada por Jordá.

Otros investigadores han intentado dar una cronología relativa a éste arte, fechándolo en diversos períodos que pueden abarcar desde el Paleolítico Superior hasta finales de la Edad del Bronce, y utilizando ciertos criterios tales como la presen-

* Este trabajo resume una parte de nuestra Memoria de Licenciatura que fue dirigida por el Dr. M. S. Hernández Pérez. Presentada en la Facultad de Filosofia y Letras de la Universidad de Alicante, mereció la calificación de Sobresaliente por unanimidad. cia de fauna cuaternaria (BREUIL, SERRANO y CABRÉ, 1912, 560), la evolución estilística (HERNÁNDEZ PACHECO, 1924, 172; RIPOLL, 1968, 180 y 192; BELTRÁN, 1982, 82), las superposiciones cromáticas (BELTRÁN, 1982, 82) y la asociación con materiales arqueológicos hallados al pie de los abrigos o en yacimientos próximos (ALMAGRO BASCH, 1946, 86-88).

El ámbito geográfico estudiado abarca Castellón, Valencia, Alicante y Murcia. El por qué elegimos el área central y el área meridional se debe al hecho de observarse unas diferencias estilísticas entre ambas áreas. Respecto a esta delimitación geográfica se plantea el problema del vacío pictórico en Alicante, lo cual nos ha llevado a conclusiones muy parciales. Como es sabido, últimamente, se han descubierto numerosos abrigos con pinturas levantinas que están en proceso de estudio $\mathrm{y}$, por ello, no se incluyen en este trabajo. Pensamos que pueden aportar nuevos datos interesantes para el estudio de nuestro arte. Esta área ha demostrado ser importante debido al descubrimiento de un nuevo arte, llamado Macro-Esquemático, que es evidentemente anterior al Arte Levantino de la zo- 
na. En Covachos de la Sarga, un meandriforme está infrapuesto a varios ciervos levantinos. Este arte es con muchas probabilidades del V Milenio a. C. (HERNÁNDEZ, 1983, 222) y, por consiguiente, posterior a los grabados paleolíticos hallados recientemente en Cova Fosca (Vall d'Ebo). Por lo tanto, el área alicantina nos ofrece una secuencia artística que permite encuadrar el Arte Rupestre Levantino después del Arte Macro-Esquemático. Actualmente, estamos a la espera de la publicación del estudio de los artes presentes en la zona de la Marina Alta y el Alcoià-Comtat, que pueden esclarecer muchas cuestiones referentes al Arte Levantino.

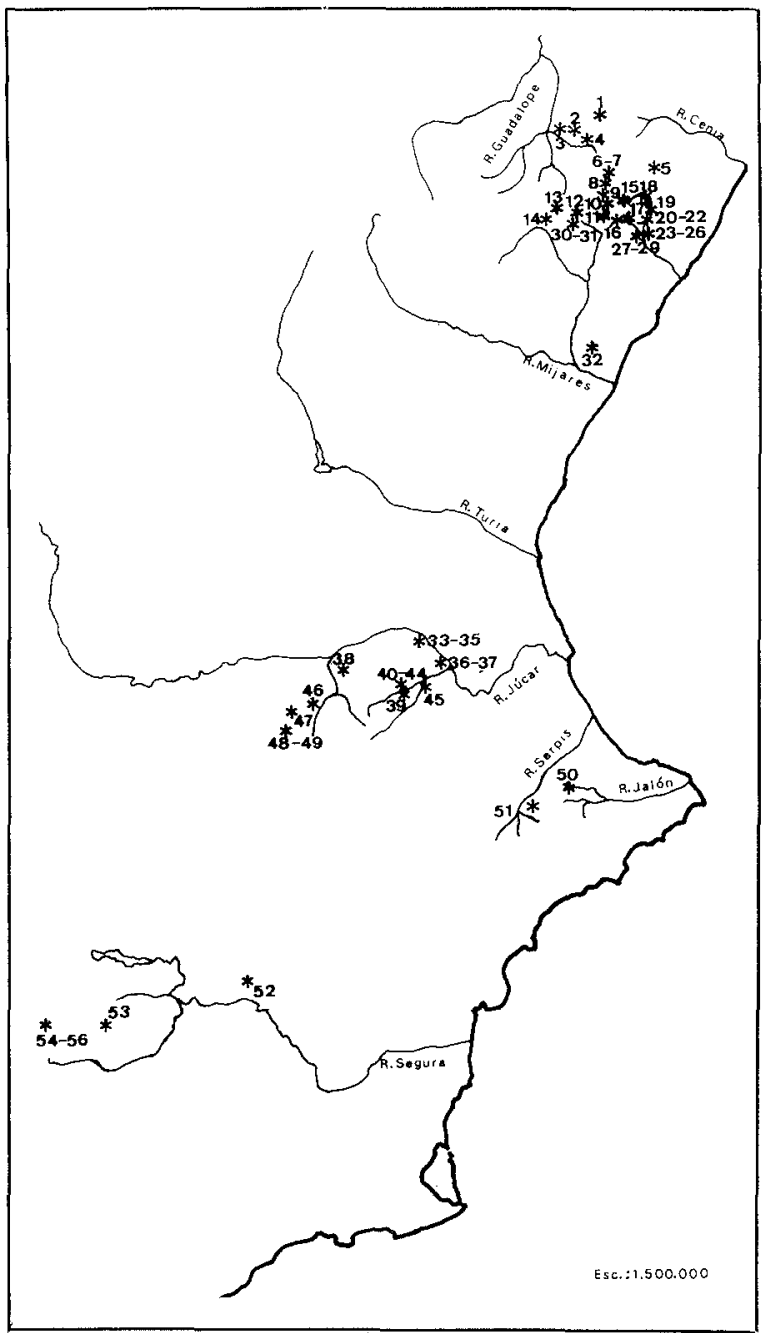

Fig. 1.-Distribución geográfica de las estaciones rupestres estudiadas.
RELACIÓN DE ESTACIONES RUPESTRES CON REPRESENTACIONES DE FIGURAS HUMANAS

\section{CASTELLóN:}

1.-Cueva del Polvorín (Puebla de Benifazá).

2.-Coveta de la Cornisa (Morella la Vieja).

3.-Galería Alta de la Masía (Morella la Vieja).

4.-Cova del Roure (Morella la Vieja).

5.-Abrigo del Mas dels Ous (Chert).

6.-Cueva Remigia (Ares del Maestre).

7.-Cingle de la Mola Remigia (Ares del Maestre).

8.-Abrigo del Racó Molero (Ares del Maestre).

9.-Abrigo de les Dogues (Ares del Maestre).

10.-Abrigo del Mas Blanc (Ares del Maestre).

11.-Abrigo del Mas del Single (Ares del Maestre).

12.-Abrigo del Racó de Gasparó (Ares del Maestre).

13.-Abrigo del Mas de la Rambla (Ares del Maestre).

14. - Covatica del Gran Pájaro (Villafranca del Cid).

15.-Coveta de Montegordo (Cuevas de Vinromá).

16.-Cingle del Mas d'en Salvador (Albocácer).

17.-Cingle de l'Ermita (Albocácer).

18.-Coves del Civil (Tirig).

19.-Coves dels Tolls Alts (Tirig).

20. - Cova del Rull (Tirig).

21.-Cova dels Cavalls (Tirig).

22. - Cova de l'Arc (Tirig).

23.-Cingle del Mas d'en Josep (Tirig).

24. - Cova Alta del Llidoner (Cuevas de Vinromá).

25.-Roques de les Calçaes del Matà (Cuevas de Vinromá).

26.-Coves de la Saltadora (Cuevas de Vinromá).

27.-Cingle dels Tolls del Puntal (Albocácer).

28. - Cova Gran del Puntal (Albocácer).

29. - Covetes del Puntal (Albocácer).

30.- Abrigo del Racó de Nando (Benasal).

31. - Cova de Montllor (Benasal).

32.-Abrigo de la Joquera (Burriol).

\section{VALENCIA}

33.-Abrigo del Ciervo (Dos Aguas).

34.-Abrigo de la Pareja (Dos Aguas).

35.- Abrigo del Cinto de la Ventana (Dos Aguas).

36.-Cueva del Cerro (Millares).

37.-Abrigo de las Cañas (Millares).

38.-Abrigo de las Monteses (Jalance).

39.-Cuevas de la Araña (Bicorp).

40.-Abrigo de las Sabinas (Bicorp).

41.-Abrigo del Garrofero (Bicorp).

42.- Abrigo de la Balsa de Calicanto (Bicorp).

43.--Abrigo Gadivia (Bicorp).

44.-Abrigo de la Madera (Bicorp).

45.-Abrigo de Boro (Quesa).

46.-Cueva del Sordo (Ayora).

47.-Cueva de Tortosillas (Ayora).

48.-Cueva del Queso (Alpera, Albacete).

49.-Cueva de la Vieja (Alpera, Albacete).

\section{ALICANTE}

50.- Abrigo de Benirrama (Benirrama).

51.-Covachos de la Sarga (Alcoy).

\section{MURCIA}

52.-Covachos de los Grajos (Cieza).

53.-Abrigo de la Risca (Moratalla).

54.- Abrigos de la Cañaica del Calar (El Sabinar, Moratalla).

55.-Friso Segundo de El Sabinar (El Sabinar, Moratalla).

56.-Abrigo de la Fuente del Sabuco (El Sabinar, Moratalla). 
Asimismo, hemos incluido dos estaciones albacetenses, Cueva del Queso y Cueva de la Vieja, por su ubicación en el Cerro del Bosque, donde se sitúa, también, Cueva de Tortosillas, estación perteneciente a Valencia. Consideramos que existe una intima relación entre los tres yacimientos por su proximidad geográfica en un mismo ambiente ecológico. De ahí que las dos estaciones albacetenses siempre aparezcan dentro del área valenciana.

Ha sido necesario determinar las actividades desempeñadas por los antropomorfos para verificar la posible relación de los elementos etnográficos con ellas. Así, diferenciamos los cazadores por aparecer en escenas cinegéticas; los arqueros, no integrados en escenas, por tener arco y/o flechas; los guerreros por ser personajes armados y enfrentados a otros; las figuras sin actividad determina$\mathrm{da}$; los/as danzarines/as por estar en actitud de baile; $y$, por último, las figuras femeninas aisladas por aparecer sin contexto.

Para el análisis etnográfico hemos formado dos grandes grupos: los adornos y los útiles, que, una vez interpretados, les ha sido aplicada una tipología en la que se distinguen tipos (designados con números romanos), subtipos (números arábigos), e incluso en ocasiones, variantes (letras minúsculas) y subvariantes (letras minúsculas y números arábigos exponentes). Nuestra tipología se ordena del siguiente modo:

1. Distinguimos los adornos de cabeza y establecemos seis tipos:

- Tipo I: Diademas.

- Tipo II: Tocados de plumas.

- Tipo III: Tocados de «dos orejitas».

- Tipo IV: Tocados altos.

- Tipo V: Máscaras.

- Tipo VI: Tocados varios.

2. Ordenamos los adornos corporales en función de su presencia en diferentes partes del cuerpo, correspondiendo a cada una de ellas un tipo:

- Tipo I: Adornos de brazos.

- Tipo II: Adornos de espalda.

- Tipo III: Adornos de cintura.

- Tipo IV: Adornos de piernas e indumentarias.

3. Se clasifican los útiles en base a su interpretación funcional:

- Tipo I: Arcos.
- Tipo II: Flechas.

- Tipo III: Recipientes.

- Tipo IV: Útiles varios.

\section{ADORNOS}

\subsection{TOCADOS}

\section{TIPO I: DIADEMAS}

Entendemos por tales las cintas que ciñen el pelo, a la altura de las sienes, con la doble función de retener y adornar el peinado. En las figuraciones no se ve y, por lo tanto, hay que basarse en un criterio para justificar su existencia. Dicho criterio se fundamenta en la presencia de un convencionalismo consistente en la formación de dos masas sobresalientes, una en cada lado de la cabeza, debido a la presión ejercida por la cinta sobre el pelo. Esto da lugar a que la cabeza tenga una forma, llamada por los autores, piriforme (BELTRÁN, 1965, 118) o triangular (BELTRÁN, 1966, 91). Ripoll (1961, 28) sugiere que se debe a la presencia de una montera.

Para acreditar la existencia efectiva de las diademas presentamos algunos casos. El arquero herido de Coves de la Saltadora (Fig. 2: 12) parece llevar un elemento circular con cuatro plumas, que está desprendiéndose de su cabeza, considerado como diadema (OBERMAIER y WERNERT, $1919,101)$. Cabria la posibilidad de interpretar este adorno como la representación convencional de un penacho de plumas (consideración hecha por M.S. HERNÁNDEZ en una entrevista). Otro arquero de la misma estación rupestre (Fig. 2: 13), un cazador de Cova dels Cavalls (Fig. 2: 14) y una mujer de Cueva de la Vieja (Fig. 6: 6) tienen dos o tres plumas y el convencionalismo de la cabeza piriforme. Los cuatro casos, aunque uno sea dudoso, nos demuestran, primero, el uso de la diadema y, segundo, la sujeción mediante ella de las plumas. Es lógico pensar que para mantenerlas erguidas se necesita un objeto que cumpla esta función. Nada más indicado que la diadema.

La materia con que estaban hechas ofrece varias posibilidades. Según Jordá $(1974,221)$ estarían formadas por dos elementos, uno interior, de corteza, madera, tela gruesa o metal, y otro exterior metálico, posiblemente oro o plata, en forma laminar. Estimamos que, aparte de poder existir 
tal tipo de diadema compuesta, pudo ser una simple cinta, que además de las materias mencionadas, fuese de cuero o fibras vegetales tejidas o no.

Dentro de las diademas levantinas distinguimos dos subtipos:

\section{- Subtipo 1.}

Es la diadema que no se observa visualmente, pero cuya existencia viene acreditada por el convencionalismo de las dos masas salientes a ambos

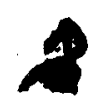

1

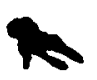

4

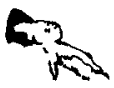

7

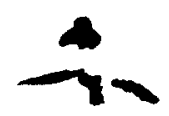

10

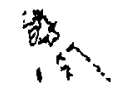

2

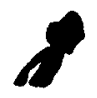

5

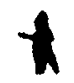

8

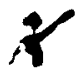

11

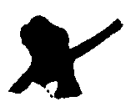

3

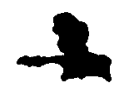

6

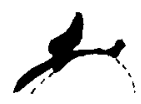

9

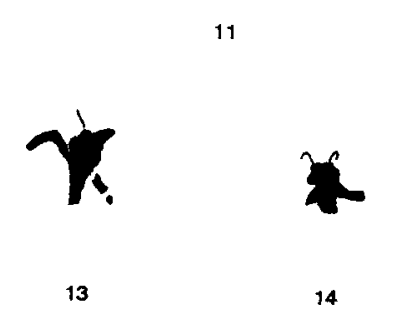

13

12

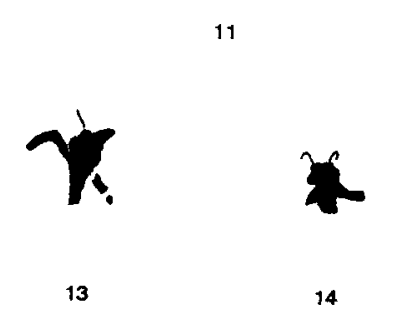

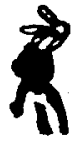

Fig. 2.-1, Cinto de la Ventana (JORDÁ y ALCÁCER, 1951); 2, El Racó Molero (RIPOLL, 1963); 3, EI Mas d'en Josep (DURÁN y PALLARÉS, 1915-20); 4, El Racó de Nando (GONZÁLEZ, 1974); 5, Montllor (VIÑAS, SARRIÀ y MONZONIS, 1979); 6, 10-11, Cueva Remigia (CAMP ILLO y VIÑAS, 1980; MARCONELL, 1953; PORCAR, 1934); 7, El Polvorín (VILASECA, 1947); 8, La Araña (HERNÁNDEZ, 1924); 9, La Mola Remigia (RIPOLL, 1963); 12-13, La Saltadora (OBERMAIER y WERNERT, 1919); 14, Els Cavalls (OBERMAIER y WERNERT, 1919). lados de la cabeza, cuando la figura aparece en posición frontal (Fig. 2: 1-3, 6, 10-11; Fig. 6: 1-2), o de una protuberancia en la nuca, cuando su posición es de perfil (Fig. 2: 4-5, 7-9). Todas las figuras nombradas suelen llevar una melena corta que explicaría el uso de la diadema para ceñir el pelo.

\section{- Subtipo 2.}

Se caracteriza por la presencia del convencionalismo explicado arriba pero, además, asociado a plumas (Fig. 2: 13-14; Fig. 6: 6). Sin embargo, el arquero herido de Coves de la Saltadora (Fig. 2: 12) no tiene la cabeza piriforme y lleva una supuesta diadema con cuatro plumas. Habría que cuestionarse sobre la asociación cabeza piriformediadema. Tal vez, la solución esté en el largo del pelo. Si la figuración lleva melena corta, al ceñirla con una cinta tenderá a formar dos protuberancias laterales. Si por el contrario, el pelo es más corto, no se dará tal tendencia.

Las diademas se reparten por Castellón, Murcia y Valencia, predominando en esta última área. En Alicante están totalmente ausentes hasta el momento.

Suelen llevarlas los cazadores, los recolectores, las figuras masculinas y femeninas sin actividad precisada, los arqueros y las figuras femeninas aisladas, siendo en estos dos últimos grupos donde aparecen con más frecuencia.

- Cronología relativa.

Los paralelos muebles hallados son las diademas metálicas, por ser las únicas que se conservan, procedentes del enterramiento múltiple de la Cueva de los Murciélagos (Albuñol, Granada) (GÓNGORA, 1868, 29), de las sepulturas campaniformes de Montilla (Córdoba), Agua Branca (Portugal), Alcalá y Matarrubilla (MALUQUER, 1970, 84-86), de tumbas argáricas y del Tesorillo de Cabezo Redondo (Villena, Alicante) fechado hacia el 700 a. C. (ALMAGRO GORBEA, 1974, 89).

\section{TIPO II: TOCADOS DE PLUMAS}

Consideramos como plumas uno o varios apéndices, largos o cortos, cuya base en contacto con la cabeza suele ser estrecha.

Los problemas se presentan a la hora de distinguir, por ejemplo, un tocado de dos plumas y uno de «dos orejitas». Estas últimas parecen tener una base más ancha y una notable separación entre los dos apéndices. Los autores no hacen hincapié en su diferenciación. Otras veces hay que distinguir has- 
ta qué punto se trata de plumas o del pelo deshecho. Asimismo, hay ciertos apéndices que tienen su extremo superior doblado en ángulo agudo o en curva. Suelen llamarse «antenitas» (BELTRÁN, 1968, 195) o «puntas» (OBERMAIER y WERNERT, 1919, 50) y son interpretadas como plumas.

Conviene preguntarse sobre el elemento de sujeción para mantener enhiestas las plumas. Las diademas serían el objeto más efectivo y aceptable. $\mathrm{Si}$ la diadema estuviera formada por dos elementos, uno exterior y otro interior, las plumas se insertarían entre ambos.

En función del número de plumas, que conforman este tipo de tocado, diferenciamos cuatro subtipos:

- Subtipo 1.

Presenta un único apéndice ubicado en la coronilla de la cabeza (Fig. 3: 1-4; Fig. 6: 4). Puede ser más o menos estrecho $\mathrm{y}$ manifestarse inclinado (Fig. 3: 1-3; Fig. 6: 4).

\section{- Subtipo 2 .}

Consiste en dos apéndices, unas veces filiformes y otras más anchos, rectos o inclinados, tanto hacia adelante como hacia atrás, cuya base es estrecha, y situados en la coronilla de la cabeza (Fig. 3: 5-10).

Dentro de este subtipo distinguimos: la Variante a, los apéndices son filiformes, rectos (Fig. 3: 5) $o$ inclinados (Fig. 3: 6), y largos; la Variante b, los apéndices son fỉliformes acabados en ángulo (Fig. 3: 7) o en curva (Fig. 3: 8) y reciben el nombre de «puntas» o «antenitas» por los autores mencionados anteriormente; la Variante $\mathrm{c}$, los apéndices son cortos, con sus bases cercanas y un poco más anchas que en las otras variantes. Suelen confundirse con los tocados de «dos orejitas» que, también, son dos apéndices cortos con bases anchas, pero éstas se hallan muy separadas entre sí. Ello sería un convencionalismo para representar «orejitas». En esta variante, las dos plumas pueden presentar los extremos superiores redondeados (Fig. 3: 9) o triangulares (Fig. 3: 10).

\section{- Subtipo 3.}

Son tocados con tres apéndices, de largura y anchura variable, situados en la coronilla y, en algún caso, en la región parietal y occipital según la posición de la figuración (Fig. 3: 11-14). Si se representa de frente, las tres plumas se abren en abanico (Fig. 3: 13) ubicadas en la coronilla; si está de perfil se localizan en la coronilla (Fig. 3: 12) y/o en la zona parietal (Fig. 3: 14) y occipital (Fig. 3: 11).
Hay casos donde aparecen únicamente en la región occipital (Fig. 6: 5). Por último, existe otra forma de llevar las plumas: hincadas en un lado de la cabeza (Fig. 6: 6).

En este subtipo diferenciamos: la Variante a, los apéndices son filiformes, unos más largos que otros, representados tanto en figuras vistas de frente como de perfil (Fig. 3: 11-13). En las figuraciones con la primera posición están situados, formando abanico, en la coronilla de la cabeza (Fig. $3: 13)$ y en un ejemplar se reúnen en un lado de ésta (Fig. 6: 6). Si están de perfil, suelen localizarse en la coronilla (Fig. 3: 12) y en las regiones parietal (Fig. 18: 7) y occipital (Fig. 3: 11). La Variante b, los apéndices, cortos o largos, son más anchos que en la Variante a, y situados en la coronilla, en la región parietal (Fig. 3: 14) y en la occipital (Fig. 6: 5), si la figura está de perfil. Si su posición es de frente, las plumas se abren en abanico sobre la coronilla (PORCAR, BREUIL y OBERMAIER, 1935, lám. XXXVIII, n. $\left.{ }^{\circ} 10\right)$.

- Subtipo 4.

Indica la presencia de cuatro o más apéndices, largos o cortos, situados de diversas maneras según la posición de la cabeza. Si está de frente, las plumas se abren en abanico sobre la coronilla (Fig. 3: 15-16); por el contrario, si se representa de perfil forman un penacho, con tendencia a inclinarse hacia atrás, cuyas plumas se despliegan desde la región frontal hasta la occipital (Fig. 3: 17-22). A pesar de la diferencia que hacemos entre plumas abiertas en abanico y las que forman un penacho, consideramos que corresponden a dos convencionalismos para representar un mismo tocado de varias plumas según esté de frente o de perfil.

Se distinguen: la Variante a, los cuatro (Fig. 3: 15) o más apéndices (VILASECA, 1947, lámina XXIII, Grupo n. ${ }^{\circ} 18$ ) conforman un abanico sobre las coronillas de las cabezas vistas de frente; la Variante b, los cuatro o más apéndices (Fig. 3: 18-21) están situados en las regiones parietal (Fig. 3: 17), frontal (Fig. 18 y 20) y occipital (Fig. 19 y 21) de las cabezas representadas de perfil. Las plumas tienden a inclinarse hacia atrás y a estar muy juntas. La Variante c designa aquellos tocados de varias plumas con cierta complejidad que las diferencia de las demás variantes. Es el caso de un arquero de Cueva Remigia (Fig. 3: 22) que, además de llevar tres grandes plumas curvadas hacia atrás en la región parietal de la cabeza de perfil, presenta en la zona frontal un apéndice ancho terminado en tres pequeñas prolongaciones. 
En la distribución geográfica de los casos masculinos se observa que el mayor número de ejemplares del Tipo II se localiza en Castellón, aunque con una especial preferencia por los Subtipos 2 y 3 . El área valenciana presenta menos número de ejemplares de los cuatro subtipos y algunos de ellos (1 y 4) prevalecen sobre los castellonenses. Tanto en Alicante como en Murcia existen pocas figuraciones con tocados de plumas. Solamente se contabilizan dos casos: el Subtipo 1 para un antropo-

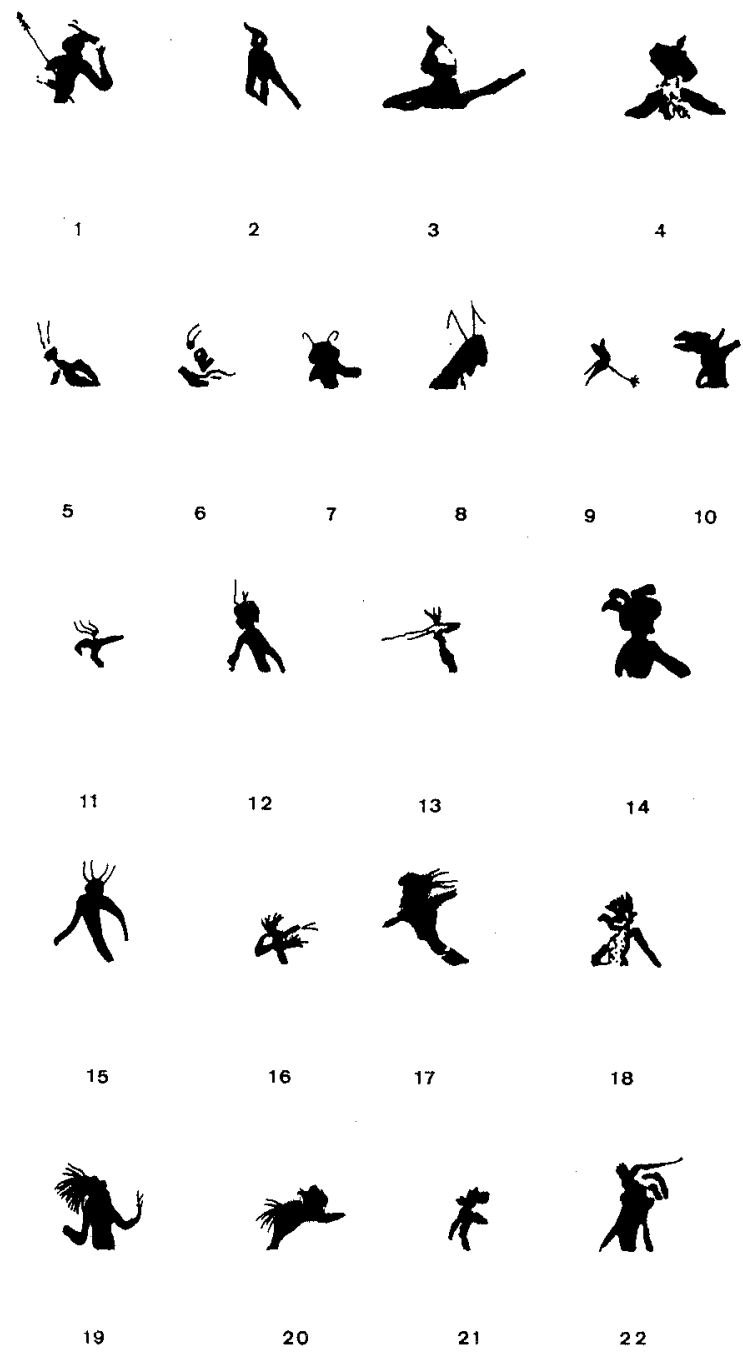

Fig. 3.-1-3, 5, 17 y 22, Cueva Remigia (PORCAR, OBERMAIER y BREUIL, 1935; JORDÁ, 1974; 1970-71; PORCAR, 1934); 4, La Sarga (BELTRÁN, 1974); 6, $11,13,16$ y 21, Les Dogues (PORCAR, 1953); 7, Els Cavalls (OBERMAIER y WERNERT, 1919); 8 y 12, El Polvorín (VILASECA, 1947); 9, 19-20, La Vieja (CABRÉ, 1915); 10, Mas d'en Josep (VIÑAS, 1981); 14, La Mola Remigia (RIPOLL, 1963); 15, El Civil (OBERMAIER y WERNERT, 1919); 18, Gadivia (MONZONIS y VIÑAS, 1980). morfo de Covachos de la Sarga y el Subtipo 2 para un cazador de Abrigos de la Cañaíca del Calar.

Los casos femeninos, que únicamente llevan los Subtipos 1 y 3, están representados mayoritariamente en Valencia. Son inexistentes en Castellón y Alicante. En Murcia sólo hay un ejemplar del Subtipo 3, concretamente en Abrigo de la Fuente del Sabuco.

Las actividades que suelen desempeñar las figuras masculinas con tocados de plumas son variadas. Los cazadores lucen todos los subtipos, especialmente el Subtipo 2. Los guerreros están representados con los Subtipos 2, 3 y 4, siendo este último el preferido. Los arqueros llevan todos los subtipos sin predominar claramente su gusto por uno de ellos en concreto. Los pocos recolectores existentes suelen adornarse exclusivamente con el Subtipo 2. Sólo tenemos un danzarín que luce tocado de plumas del Subtipo 3. Las figuras sin actividad determinada muestran tres subtipos $(2,3 \mathrm{y}$ 4), pero sin una predilección destacada por alguno. En general, el mayor número de ejemplares corresponde a los cazadores, seguido de los arqueros y los guerreros.

Las figuras femeninas con tocados de plumas suelen participar en escenas de danza, con el Subtipo 1, e indeterminadas, con el Subtipo 3. Asimismo, aparecen representaciones aisladas con este último subtipo. El mayor número de ejemplares se halla en las mujeres sin actividad precisada con el Subtipo 3.

- Cronología relativa.

Existen paralelos figurativos en el Arte Esquemático peninsular (ACOSTA, 1968, 144, f. 43; 147 , f. $45 ; 149$, f. $46 ; 152$, f. $48 ; 153$, f. 49 ; JORDÁ, 1970-71, 52-58, f. 12-15), así como en el Mediterráneo Oriental: figurilla de bronce de la región Siro-Capadocia (segunda mitad del II Milenio a. C.), una representación sobre azulejo del Templo de Medinet Habú (época de Ramsés III), la cabeza humana del Disco de Phaistós (1650-1600 a. C.) y una estatuilla de Decimoputzu (S. VIII a. C.) (JORDÁ, 1970-71, 61-65). A partir de ellos, la cronología relativa obtenida nos indicaría una fecha postquem a 1650 a. C. Jordá, que en 1970-71 opinaba que los tocados de plumas tenían un origen oriental y una datación a partir de 1200 a. C. -apoyándose en paralelos figurativos mediterráneos-, últimamente (1983, 20-34 y Cuadro Sinóptico) ha revisado su cronología relativa olvidándose de dichos paralelos, y proponiendo, en base a las fases dadas por las estratigrafías pictóricas de tres 
estaciones rupestres, una datación a partir del 3500 a. C. Según el autor dicha fecha marcaría el final de la etapa de transición del Neolítico al Eneolítico. Esta cronología contrasta notablemente con la propuesta por Martí $(1983,27-28)$ y Bernabéu (1982, 127-128) en base a sus recientes investigaciones en el País Valenciano. Sus hipótesis indican una etapa de transición, llamada Neolítico Final, que abarcaría desde el $3500 / 3400$ hasta el $2500 / 2400$ a. C.

\section{TIPO III: TOCADOS DE «DOS OREJITAS»}

Este tipo está representado como dos apéndices cortos, más o menos anchos, separados entre sí y cuya base, a veces, es amplia (Fig. 4: 1-4; Fig. 6: 3).

El problema se plantea a la hora de distinguir un tocado de «dos orejitas» de uno de dos plumas (Subtipo 2). La diferencia estriba, sobre todo, en la separación entre los apéndices, que será mayor en el primer caso, y en las bases, que serán más estrechas en el segundo caso. Conviene señalar que quizás, estemos en algunas ocasiones ante representaciones de cuernos (Fig. 4: 1 y 4) en forma de media luna.

El material con que estaban hechas las «dos orejitas», en el supuesto de que sean tales, sería el propio de las orejas de animales. Acerca del modo de sujeción, se ha sugerido que era por medio de casquetes (BELTRÁN, 1982, 42) o monteras (RIPOLL, 1961, 28). A ello añadimos la posibilidad de estar sujetas a una diadema.

Se diferencian dos subtipos:

- Subtipo 1.

Son dos apéndices cortos, anchos y delgados, de bases relativamente estrechas y separadas entre sí. El extremo superior presenta una forma redondeada (Fig. 4: 1-2). A su vez se aprecia una Variante a cuando los apéndices son más anchos y menos separados que en la Variante b (Fig. 4: 1), presentando ésta el convencionalismo de dos apéndices estrechos cuyas bases están muy separadas (Fig. 4: 2). Puede confundirse con la Variante c del Subtipo 2 de los tocados de plumas. Anteriormente ya expusimos la diferencia al tratar dicha variante. También, hay una Variante $\mathrm{c}$ que se distingue de las demás por llevar adornos complementarios. Únicamente se registra un ejemplar en un arquero de Cova dels Cavalls (Fig. 4: 3). De los dos apéndices gruesos y cortos surgen, según Obermaier y Wernert $(1919,100)$, dos hileras de dientes o con- chas, que nosotros consideramos los restos de dos posibles plumas filiformes curvadas hacia atrás.

- Subtipo 2.

Se trata de dos apéndices cortos, de bases amplias, y cuyos extremos superiores apuntados tienden a separarse en direcciones contrarias (Fig. 4: 4-5; Fig. 6: 3). Se diferencia: la Variante a, que sólo se distingue de la Variante $b$ en que no lleva adornos complementarios (Fig. 4: 4; Fig. 6: 3). Tal vez, haya ciertos casos que se asemejen a tocados de pequeños cuernos en forma de media luna. La Variante $b$, además de los apéndices, aparecen otros adornos (Fig. 4: 5) que, en el único ejemplar conocido, resultan ser dos plumas filiformes, hincadas en un espacio que queda entre ambos apéndices, e inclinadas hacia atrás.

El Tipo III está abundantemente representado en Valencia, Alicante y Murcia, y es escaso en Castellón.

Suele figurar en los cazadores, guerreros y sobre todo, en los arqueros, las figuras masculinas sin actividad precisada y las danzarinas.

- Cronologia relativa.

Es imposible establecerla, por el momento, por falta de paralelos figurativos y muebles, tanto peninsulares como de otras zonas geográficas.

\section{TIPO IV: TOCADOS ALTOS}

Consideramos como tales, una especie de sombrero o bonete de diverso formato que presenta como característica su altura. Se representan exclusivamente en figuras masculinas, no conociéndose en las femeninas.

No ofrecen ningún tipo de problema al poderlos distinguir perfectamente, y sin ninguna duda, puesto que se diferencian de la cabeza sin llegar a confundirse con la prolongación de ella, en cuyo caso resultaría exagerada.

El material empleado en su confección es difícilmente determinable. Pudo ser cuero, esparto tejido, quizás, a veces combinado con elementos metálicos. Pero son meras suposiciones sin base arqueológica.

Distinguimos seis subtipos:

- Subtipo 1.

Es un tocado alto rectangular con el aspecto de ser cilíndrico (Fig. 4: 6).

- Subtipo 2.

Presenta una forma trapezoidal, con el lado más pequeño en contacto con la cabeza. El único 
ejemplar existente sólo está contorneado y simula ser un armazón (Fig. 4: 7).

- Subtipo 3.

Es un tocado alto cónico, en unos casos más alargado (Fig. 4: 8) y en otros más corto (BELTRÁN, 1969, f. 3).

- Subtipo 4.

Indica un tocado alto terminado en dos gruesos apéndices agudos (Fig. 4: 9).
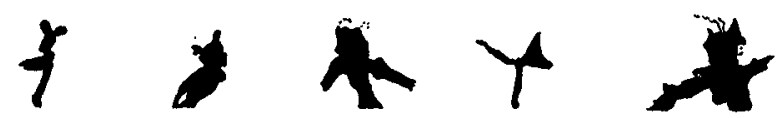

1

2

3

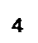

5
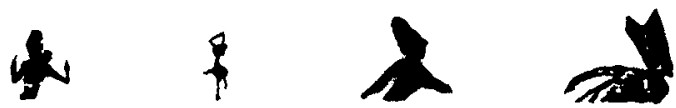

6
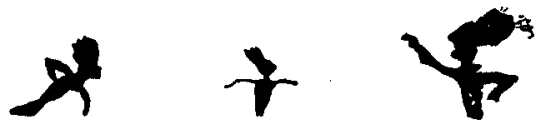

10

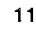

12

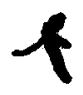

13

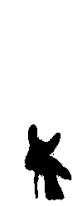

17

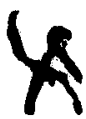

18

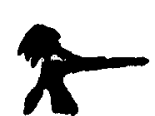

19

Fig. 4.-1, 4, 7, 14-15, La Vieja (CABRE, 1915); 2, 5, 10-11, 18-19, Cueva Remigia (PORCAR, OBERMAIER y BREUIL, 1935; JORDA, 1970-71; PORCAR, 1934); 3 y 13, Els Cavalls (OBERMAIER y WERNERT, 1919); 6 y 17, La Mola Remigia (RIPOLL, 1963); 8 , El Ciervo (JORDA y ALCÁCER, 1951); 9, La Joquera (PORCAR, 1932); 12, Boro (BELTRÁN, 1979); 16, El Racó Molero (RIPOLL, 1963).

\section{- Subtipo 5.}

Es un tocado de diversas formas acabado en varios apéndices. Se diferencian: la Variante a, presenta tres apéndices cortos en la cúspide del tocado. Tal vez se trate de pequeñas plumas. El tocado tiene una forma cilíndrica, abombada en el centro (Fig. 4: 10), una trapezoidal (Fig. 4: 11) y una rectangular (PORCAR, 1934, f. 3). La Variante $b$, en el único caso conocido, es un tocado cilíndrico, abombado en el centro, y con varios apéndices largos y filiformes que posiblemente sean plumas (Fig. 4: 12).

- Subtipo 6.

Designa una serie de tocados altos de difícil interpretación. Unos parecen tener una borla en la cúspide (Fig. 4: 13) o un apéndice (¿pluma?) (Fig. 4: 14) y otros una visera occipital (Fig. 4: 15). En este último caso se asemeja a una especie de capirote.

En la distribución geográfica aparece en Castellón, Valencia, predominando en esta área, y Murcia. En Alicante está ausente.

Suelen llevarlo los danzarines, los arqueros, los guerreros, las figuras sin actividad determinada y, sobre todo, los cazadores.

- Cronología relativa.

Para el Subtipo 1 hay cierta semejanza con el personaje del relieve del Santuario de Yazilikaia (Anatolia). En opinión de Jordá $(1966,67)$ ello implica una influencia anatólica-hitita que se fecharía a partir del 1500 a. C.

El Subtipo 5 tiene su paralelo figurativo en el gorro troncocónico con tres grandes plumas de un rey-sacerdote, representado en un fresco del Palacio de Cnossos, datado entre el 1550 y 1450 a. C. (JORDÁ, 1970-71, 67).

Estos datos inducen a pensar que los tocados altos fueron una importación del Mediterráneo Oriental, pero no hay que descartar la posibilidad de la autoctonía.

\section{TIPO V: MÁSCARAS}

Algunas representaciones humanas masculinas presentan rasgos zoomorfos, hocico y cuernos o pico de pájaro, que hacen pensar en el simulacro de un animal. Destaca el número escasísimo de este tipo de representación, conociéndose actualmente sólo cuatro ejemplares en el área estudiada.

Se distinguen dos subtipos: .

- Subtipo 1. 
Indica una cabeza humana con rasgos zoomorfos que representan un bóvido. Figuran el hocico, las orejas y, a veces, los cuernos pueden estar presentes (Variante a) (Fig. 4: 16) o no (Variante b) (Fig. 4: 17).

- Subtipo 2.

La cabeza presenta un largo pico y una morfología craneana de pájaro. Esta máscara puede tener tres plumas inclinadas, situadas en la región occipital (Variante a) (Fig. 4: 19), o bien faltar éstas (Variante b) (Fig. 4: 18).

Absolutamente todos los ejemplares están localizados en Castellón y, además, todos concentrados en tres estaciones rupestres del Barranc de la Gasulla: Cueva Remigia, Cingle de la Mola Remigia y Abrigo del Racó Molero.

- Cronología relativa.

Dentro del mismo Arte Rupestre Levantino encontramos un paralelo en Abrigo de la Peña Escrita (Villar del Humo, Cuenca). Perteneciente al Arte Esquemático peninsular hay una figura humana en Abrigo III de la Mortaja o de los Cortijos (Minateda, Albacete) que lleva cuernos liriformes. Posiblemente sea una máscara, aunque también podría tratarse de un casco con tales adornos (JORDÁ, 1975 c, 211). Existe en el Covacho III de la Sarga una figuración que ha sido siempre considerada como la representación de una figura humana perteneciente al Arte Esquemático y fechada en la Edad del Bronce (BELTRÁN, 1974, 21). Es idéntica a las grandes representaciones antropomorfas, descubiertas en el Barranc de Malafí, que son anteriores al Arte Levantino, y corresponden al nuevo tipo de arte denominado provisionalmente Arte Macro-Esquemático (HERNÁNDEZ y CENTRE D'ESTUDIS CONTESTANS, 1982, 180 y $187 ; 1983,68)$ de probable cronología neolítica (HERNÁNDEZ, 1983, 222).

En el Mediterráneo Oriental existen divinidades con cuernos en Mesopotamia, Egipto y Chipre. En concreto se pueden citar: "el antropomorfo revestido de toro de las placas del arpa de Ur» y la «figura de dios cornudo de Enkomi» (JORDÁ, 1976, 212 y 214). El primer ejemplo se data en la primera mitad del III Milenio (PARROT, 1981, 131, lám. 122); el segundo puede ser de principios del S. XII a. C. (KARAGEORGHIS, 1971, 149). Estos paralelos son efectivos hasta cierto punto, puesto que, aparte de tener posiblemente en común el significado religioso, no se asemejan formalmente a nuestras representaciones.
Respecto a las máscaras de pájaro, sólo hemos hallado una figuración humana, cuya cabeza es de pájaro, perteneciente a la Grotte de Lascaux, que Leroi-Gourhan $(1978,258$, f. 74) encuadra en su estilo III. Este yacimiento ha sido fechado en el Magdaleniense I-II (LEROI-GOURHAN, 1978, 454).

Otro tipo de máscaras zoomorfas aparece, por una parte, en el «brujo» disfrazado de reno de la Grotte des Trois Frères, del estilo IV, datado en el Magdeleniense III-IV según Leroi-Gourhan (1978, 310, f. 57). Por otra parte, en el Arte Rupestre Sahariano, existen hombres enmascarados asociados a dos tipos de escenas, de caza y de fecundidad, que corresponden, únicamente, al Período Bubalino o de los Cazadores del V Milenio y, tal vez, del VI (HUGOT, 1974, 248 y 275).

\section{TIPO VI: TOCADOS VARIOS}

Engloba una serie de tocados con morfología extraña y con escaso número de ejemplares en cada subtipo diferenciado.

La cuestión principal radica en establecer una definición exacta para estos adornos. Dentro de ellos existen varios tocados polémicos: los adornos colgantes (OBERMAIER y WERNERT, 1919, 100-101) de una figura de Coves del Civil (Fig. 5: 1) y otra de Cingle del Mas d'en Josep (Fig. 5: 3), el casco del jinete del Abrigo X de Cingle de la Mola Remigia (Fig. 5: 9) y los posibles tocados de cuernos (JORDÁ, 1970-71, 51 y 72).

Se diferencian siete subtipos:

- Subtipo 1.

Se trata de un conjunto de puntos diminutos localizados a ambos lados de la cabeza (Fig. 5: 1) o en la coronilla (Fig. 5:2) o región parietal (Fig. 5: $3)$. Tales puntos han sido considerados como colgantes de conchas o de dientes perforados (OBERMAIER y WERNERT, 1919, 100; BELTRÁN, 1982, 42). Realmente, en dos de los tres casos conocidos, se trata de restos de pintura que en su día fueron plumas (Fig. 5:2-3). En base a esta afirmación distinguimos: la Variante a, representada por una serie de líneas de puntos que cuelgan a ambos lados de un peinado (Fig. 5: 1). Posiblemente, sean colgantes de conchas, dientes o cuentas. La Variante $b$ señala dos o tres líneas de puntos que salen, en un caso, de un tocado de «dos orejitas» (Fig. 5: 2) y, en otro, de la zona parietal (Fig. 5: 3). Sin duda son lo que queda de las plumas filiformes. 
- Subtipo 2.

Se trata de una serie de tocados cuyo denominador común es el ser planos. En la Variante a, el tocado tiene una forma trapezoidal y, en general, no sobresale a ambos lados de la cabeza (Fig. 5:4), aunque, en ocasiones, parece tener una visera delantera (Fig. 7: 7). La Variante b son tocados con forma oblonga, cuyos extremos laterales sobresalen de la cabeza (Fig. 5: 5; Fig. 6: 8). Hay un caso excepcional que muestra sólo la línea de contorno pintada (Fig. 5: 6).

\section{- Subtipo 3.}

Es un tocado que recuerda un sombrero de copa (Fig. 5: 7).

- Subtipo 4.

Indica un tocado de forma triangular que puede ser más (VILLAVERDE, PEÑA y BERNABÉU, 1981, 312, f. 4) o menos alto (Fig. 5: 8; Fig. 6: 7). Tal vez, esta forma triangular represente el convencionalismo de una melena corta.

\section{- Subtipo 5.}

Designa el casco del jinete del Abrigo X de Cingle de la Mola Remigia (Fig. 5: 9). Aunque sea un tocado triangular, se diferencia del Subtipo 4 en que se separa claramente de la cabeza.

- Subtipo 6.

Dentro de él englobamos todo tipo de tocado complejo de difícil descripción. Los ejemplares son variados y diferentes unos de otros. Cada uno es excepcional en sí. Los hay que tienen una serie de apéndices cortos y largos (Fig. 5: 10-11) que no representan plumas. Otros presentan una media luna terminada en tres apéndices pequeños (Fig. 5:12) o llevan una especie de mantilla (Fig. 5: 13) (JORDÁ, 1975 b , 172) o lo que parece un holmo medieval (BELTRÁN, 1972, f. 55). Una figura de Cueva Remigia luce dos gruesas protuberancias globulares y en medio dos apéndices anchos (¿plumas?) (MARCONELL, 1953, 21, f. 5). Una mujer de Abrigo del Racó de Gasparó (Fig. 6: 10) presenta «una corona con plumas de faisán» (PORCAR, $1965,178)$. Otra lleva un tocado formado por una protuberancia a cada lado de la cabeza (Fig. 6: 9). Por último, una figura femenina tiene dos apéndices lineales salientes de la nuca (Fig. 6: 11) que, quizá, sean elementos de sujeción para el pelo.

- Subtipo 7.

Clasifica lo que consideramos, con ciertas reservas, tocados de cuernos. Están representados por dos apéndices largos (Fig. 5: 14, 16-17) o cortos (Fig. 5: 15), de extremos apuntados (Fig. 5: 1415) o no (Fig. 5: 16-17). Se distinguen de las másca- ras de bóvidos en que no presentan cabeza zoomorfa. Posiblemente, estuviesen montados sobre gorros de cuero a modo de casco.

El Tipo VI de los tocados, excepto los Subtipos 5 y 7 , se reparte por Valencia, Alicante, Murcia y
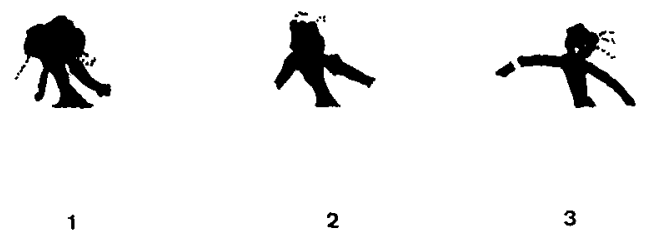

2

3
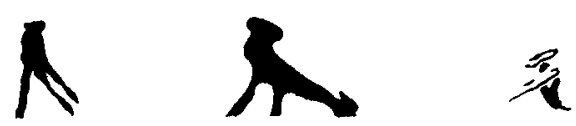

4

5

6
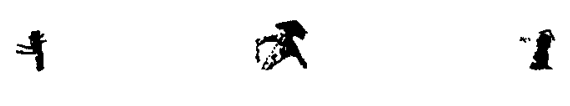

7

8

9
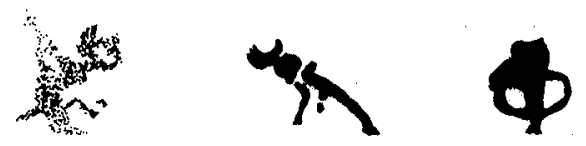

11

12

13
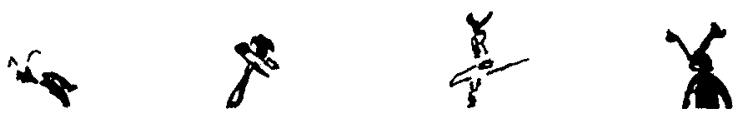

14

16

17

Fig. 5.-1, El Civil (OBERMAIER y WERNERT, 1919); 2, Els Cavalls (OBERMAIER y WERNERT, 1919); 3, El Mas d'en Josep (OBERMAIER y WERNERT, 1919); 4, El Garrofero (MONZONIS y VIÑAS, 1980); 5, El Ciervo (JORDÁ y ALCÁCER, 1951); 6 y 15, Les Dogues (PORCAR, 1953); 7, 9, 11 y 16, La Mola Remigia (RIPOLL, 1963); 8, La Saltadora (RIPOLL, 1970); 10, El Polvorín (VILASECA, 1947); 12, 14 y 17, Cueva Remigia (PORCAR, 1934; PORCAR, OBERMAIER y BREUIL, 1935; CAMPILLO y VIÑAS, 1980); 13, Los Grajos (BELTRÁN, 1969). 
Castellón, siendo exclusivos de esta última área los dos subtipos mencionados.

Suelen llevarlo preferentemente los danzarines, arqueros y cazadores, aunque, también, aparece en los guerreros, recolectores, figuras femeninas aisladas, así como en los hombres y mujeres sin actividad precisada. Las representaciones femeninas únicamente están representadas con los Subtipos 2 (Variante b), 4 y 6.

\section{- Cronología relativa.}

Por falta de paralelos muebles y figurativos, no se puede dar una cronología relativa a la mayoría de los tocados varios, excepto a los Subtipos 5 y 7 , e incluso este segundo, al ser todavía una hipótesis de trabajo, su posible presencia no permite aportar datos a este respecto.

El jinete de Cingle de la Mola Remigia llama la atención por montar un caballo con brida y por cubrirse con un casco. En base a la primera consideración, Ripoll $(1962,93)$ lo fecha a finales de la Edad del Bronce. Por la segunda consideración, Almagro Basch $(1966,170-172)$ encuentra su paralelo en los cascos de tipo de cimera con peine, representados en las estelas decoradas del Suroeste fechadas a partir del S. VIII a. C. Por su parte, Almagro Gorbea, que en un principio lo relacionaba con los cascos Tipo Huelva de origen europeo y datados en torno al 900 a. C. $(1973,356)$, recientemente ha hecho hincapié en la presencia del caballo guiado con bridas, fenómeno generalizado en el Período Hallstatt C, y en la semejanza del casco con los representados en figuras ecuestres del Norte de Italia y la zona alpina. De todo ello deduce que la figura levantina se debe fechar a partir del S. VIII a. C. (1977, 121-122).

Se plantean dos problemas al intentar asemejar y fechar el casco de nuestro jinete con los de la Edad del Hierro y su cronología. Primero, habría que ver hasta qué punto lleva un casco y no otro tipo de adorno. Por el hecho (discutible) de montar un caballo con brida, parece lógico y posible que lleve un casco, puesto que no saldría del contexto cultural que supone la monta del caballo. Segundo, habría que cuestionarse sobre la pertenencia de esta figura al Arte Rupestre Levantino, ya que es una figura excepcional, cuya representación, según Ripoll $(1962,93)$, sería el fruto del impacto que debió producir en los indígenas la aparición del caballero representante de pueblos colonizadores. En este caso se podría considerar como una última manifestación del Arte Levantino. Si por el contra- rio no pertenece a dicho arte, cabría la posibilidad de hallarnos ante una figura aislada de la Primera Edad del Hierro del área levantina.

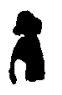

1
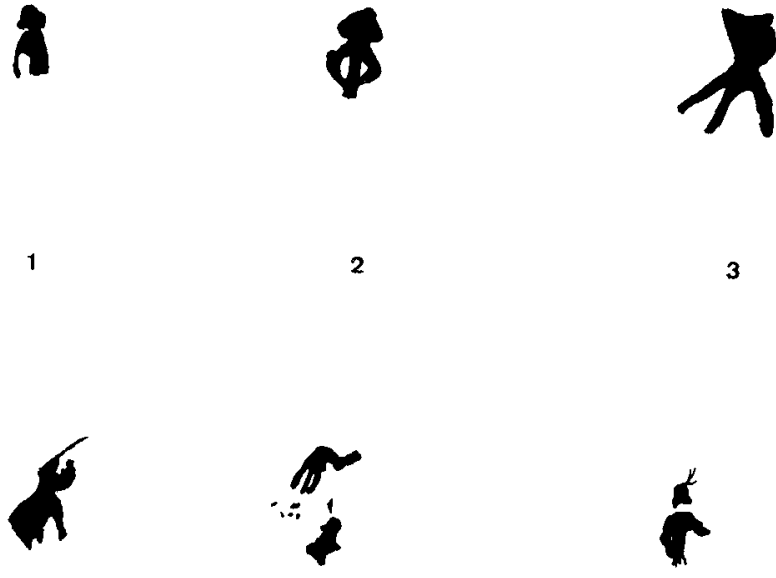

4

5

6
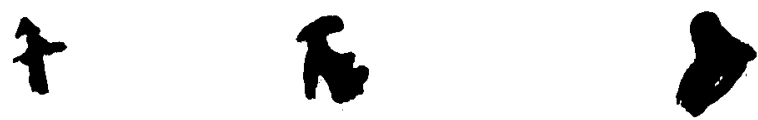

7

8

9
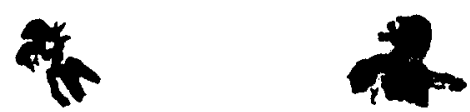

10

11

Fig. 6.-1, La Fuente del Sabuco (BELTRÁN, 1972); 2, Gadivia (MONZONIS y VINAS, 1980); 3, Los Grajos (BELTRÁN, 1969); 4 y 8, El Ciervo (JORDÁ y ALCÁCER, 1951); 5, La Madera (MONZONIS y VIÑAS, 1980); 6 y 9, La Vieja (CABRÉ, 1915); 7, Benirrama (ASQUERINO y C. E. C., 1981); 10, El Racó de Gasparó (PORCAR, 1965); 11, La Pareja (JORDÁ y ALCÁCER, 1951). 


\subsection{ADORNOS CORPORALES}

\section{TIPO I: ADORNOS DE BRAZOS}

La presencia de adornos en las extremidades superiores es probable si observamos atentamente las pocas figuras que presentan o bien abultamientos o apéndices largos que sobresalen de sus bra-
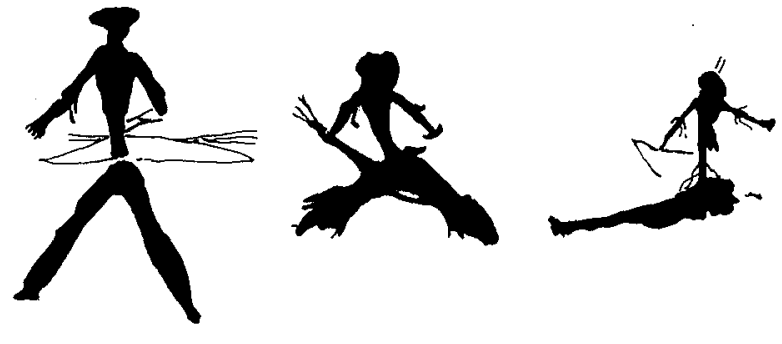

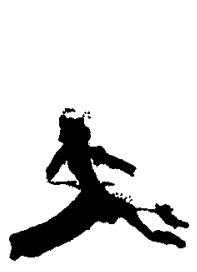

2

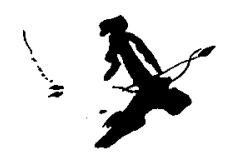

4

5

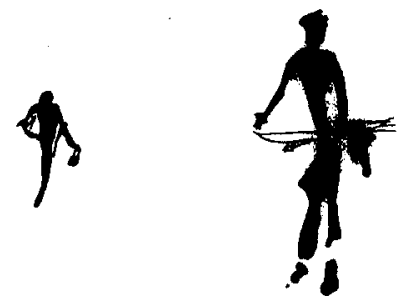

6

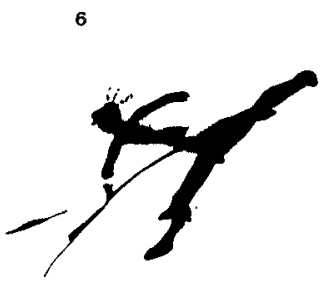

9
7

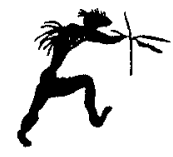

10
Fig. 7.—1 y 7, El Ciervo (JORDÁ y ALCÁCER, 1951); 2, El Mas dels Ous (APARICIO, MESEGUER y RUBIO, 1982); 3, La Saltadora (VIÑAS, 1979-80); 4-5, Els Cavalls (OBERMAIER y WERNERT, 1919); 6, EI Civil (OBERMAIER y WERNERT, 1919); 8, La Araña (HERNÁNDEZ, 1924); 9, El Mas d'en Josep (OBERMAIER y WERNERT, 1919); 10, La Vieja (CABRE, 1915). zos. No obstante, cabe plantearse ciertas dudas con respecto a los abultamientos. Éstos pueden ser el producto del deseo del autor del calco de ver un posible brazalete; también, pueden ser los restos de un brazo más grueso originalmente. Sobre estas cuestiones no podemos decidir al no haber realizado una revisión de los calcos. Por lo tanto, consideramos que son adornos cilíndricos de brazo.

Para la fabricación de los apéndices largos pudieron emplear tiras de fibras vegetales y de cuero; para los brazaletes, piedra, hueso, concha, madera y metal.

Distinguimos dos subtipos de adornos de brazos y algunas variantes en función del formato y de la situación del objeto:

- Subtipo 1.

Son aquellos adornos caracterizados por uno o varios apéndices largos y estrechos, situados preferentemente en uno o cada codo. Opinamos que se trata de cintas colgantes. La Variante a, está representada por dos cintas en uno o ambos codos (Fig. 7: 1; Fig. 9: 4-6). La Variante b, señala la presencia de una cinta en cada codo (Fig. 7:2), en uno solo (OBERMAIER y WERNERT, 1919, lám. XI, $n .^{\circ}$ 25) o en el brazo propiamente dicho (OBERMAIER y WERNERT, 1919, lám. XXIV, $n .{ }^{\circ} 48$ ). En ocasiones parece colgar de una (Fig. 9: 1) o ambas axilas (DURÁN y PALLARÉS, 1915-20, 452 , f. 61). Conviene destacar que la cinta de la tercera figura nombrada presenta una rigidez y un ángulo anómalos y, por lo tanto, habría que plantearse hasta qué punto se trata de una cinta. La Variante $\mathrm{c}$, está formada por tres cintas localizadas en uno (Fig. 9: 2) o ambos codos (Fig. 7: 3). La Variante $d$, indica una cinta franjeada en un extremo inferior con cuatro apéndices (Fig. 9: 3).

- Subtipo 2.

Clasifica los adornos cilíndricos que figuran como abultamientos en los brazos. Pueden estar situados a mitad del brazo y en el codo, tratándose de brazaletes, o en las muñecas siendo pulseras. La Variante a, son brazaletes cuyo perfil presenta una moldura curva y se localizan a mitad del brazo, propiamente dicho, y no en el codo (Fig. 7: 4-5; Fig. 9: 7-8). Pueden aparecer en uno (Fig. 7: 4; Fig. 9: 8) o ambos brazos (Fig. 7: 5; Fig. 9: 7). La Variante $b$, se trata de brazaletes y pulseras cuyo perfil es de una moldura angular. Pueden situarse a media altura del brazo, siendo el caso de un brazalete (Fig. 7: 6), o en ambas muñecas, tratándose de pulseras (Fig. 7: 7). La Variante c, indica un brazalete con estrangulamiento central, cuyo perfil 
es de doble moldura angular. El único ejemplar registrado lo luce en el codo (Fig. 7: 8).

La distribución geográfica de los adornos de brazos señala que los dos subtipos están representados en Castellón y Valencia, pero el Subtipo 1 abunda más en la primera área y el Subtipo 2 en la segunda. Destaca la inexistencia de estos adornos en Alicante. En Murcia sólo aparece el Subtipo 1 en figuras femeninas.

Suelen estar representados con los dos subtipos: los cazadores, los guerreros, las figuras femeninas sin actividad determinada y las mujeres aisladas. En ocasiones, los arqueros llevan el Subtipo 2 y las danzarinas, así como las figuras masculinas sin actividad precisada, lucen el Subtipo 1.

- Cronología relativa.

Las cintas colgantes únicamente tienen un pararelo figurativo en una esquirla de hueso, del yacimiento magdaleniense de Forges (Bruniquel, Francia), donde está grabado un brazo humano con un adorno en forma de cinta (WERNERT, 1917, 4). Consideramos que dar una cronología concreta a dicho subtipo es casi imposible por ser un adorno atemporal debido a la simpleza de su fabricación y a la fácil obtención de su material.

Respecto al Subtipo 2, en primer lugar observamos que los brazaletes y pulseras figurados sobresalen bastante del brazo y, por consiguiente, debían tener unas secciones circulares y ovales de considerable tamaño. En segundo lugar, al mirar dichos adornos pertenecientes a diferentes culturas materiales, no hemos encontrado paralelos tipológicos evidentes. No se asemejan, en cuanto a tamaño, a los brazaletes del Neolítico, Eneolítico o de la Edad del Bronce hallados hasta el momento. Sin embargo, cabe la posibilidad de que los pintores levantinos desearan hacer resaltar tales adornos, dándoles mayor grosor, con una finalidad difícilmente explicable. Esta consideración valdría para los brazaletes de la Variante a, que de esta manera podrían adjudicarse a las tres culturas mencionadas. Respecto a los correspondientes a las Variantes $b$ y c, sus perfiles con una o dos molduras angulares parecen sugerir tipos metálicos como bien insinúa Jordá $(1978,141)$. Este autor incluso encuentra paralelos tipológicos de la Variante b en los Tipos 2, 3, 4 y 5 de los brazaletes del Tesoro de Villena (JORDÁ, 1980, 94; SOLER, 1965, 15, f. 4: 2-5). Sobre la Variante $c$ podemos decir que es igual a las ajorcas que luce un cazador de Abrigo del Ciervo (Fig. 10;2) paralelizable, según Jordá (1980, 94), con el Tipo 6 de Villena (SOLER, 1965,
15, f. 4: 6). Los brazaletes de dicho tesoro han sido fechados en la segunda mitad del S. VIII a. C. (ALMAGRO GORBEA, 1974, 70).

Resulta un hecho extraño la discordancia existente entre la zona de hallazgos de brazaletes y la zona con sus representaciones pictóricas. En efecto, los yacimientos argáricos de Murcia y los neolíticos, eneolíticos y del Bronce Valenciano de Alicante han dado un buen número de brazaletes, mientras que los situados en Castellón y Valencia, pertenecientes a estos tres períodos culturales, casi carecen de ellos. Por el momento, no tenemos una explicación lógica para esta discordancia.

\section{TIPO II: ADORNOS DE ESPALDA}

La presencia de adornos de espalda es muy discutible por su situación extraña. Beltrán $(1968,44)$ niega tal presencia y afirma que todos los casos conocidos son bolsas, mochilas, carcajes o, simplemente, flechas colgadas en la espalda. Por otra parte, Obermaier y Wernert $(1919,101-102)$ vieron adornos de cuello y espalda en forma de cintas con dos o tres «estrías».

Ante estas opiniones tan dispares, conviene analizar las únicás tres figuras masculinas que presentan ciertos objetos en la espalda. Una de ellas (Fig. 7:9) tiene representado un abultamiento, no muy grande, terminado en dos apéndices largos (cintas), del cual no salen flechas. Por consiguiente, al no presentar esta característica y, además, al no tener un formato semejante a los carcajes conocidos (Fig. 14: 1-5) descartamos que se trate de tales objetos. Podrían ser bolsas, pero tampoco conocemos que tengan la misma forma ya que las bolsas representadas son ovaladas o redondeadas (Fig. 14: 6-10). No obstante, también cabe la posibilidad de que puedan ser adornos de espalda, cuyo significado y finalidad desconocemos.

La segunda figura (Fig. 7:10) presenta una serie de líneas finas, un tanto curvadas, que salen de su espalda un poco jorobada. Si fuesen flechas colgadas, al igual que en un guerrero de Coves del Civil (OBERMAIER y WERNERT, lám. XI), no tendrían la curvatura mencionada. Por otra parte, existe una figura (Fig. 8:4) que tiene las mismas líneas curvadas, localizadas más arriba de la cintura, y tampoco parece tratarse de flechas. Por lo tanto, deben de ser adornos de espalda en forma de cintas estrechas o, tal vez, plumas.

En función del formato distinguimos dos subtipos: 


\section{- Subtipo 1.}

Es un apéndice ancho, más o menos rectangular, terminado en dos cintas de diferente largura (Fig. 7: 9).

- Subtipo 2.

Señala la presencia de varios apéndices estrechos y curvilíneos bastante largos (Fig. 7: 10).

En Castellón están representados: un ejemplar del Subtipo 1 y otro del Subtipo 2. Asimismo, este último tiene una figuración en Cueva de la Vieja, incluida en el área valenciana.

Los dos subtipos figuran exclusivamente en cazadores.

- Cronología relativa.

Es difícilmente determinable ya que no existen paralelos figurativos ni muebles y, además, los posibles materiales utilizados - fibras vegetales, cuero y plumas-, de difícil conservación, no nos aportan datos para ella por ser atemporales.

\section{TIPO III: ADORNOS DE CINTURA}

Parece ser que los autores del Arte Rupestre Levantino utilizaban adornos en la cintura con dos finalidades según el formato de éstos. Así, los denominados por nosotros cintas y protuberancias tuvieron, posiblemente, un fin utilitario. Las primeras servirían para ceñir los probables estuches fálicos y los pantalones, mientras que las segundas se asocian a estos últimos y a los taparrabos. Existe un caso curioso en una figura femenina con falda (Fig. 9: 9) que lleva ambos modos de atadura.

La finalidad de las cintas está clara, pero respecto a las protuberancias se podría suponer que fuesen la representación de nudos o de algún otro tipo de atadura (por ejemplo, broches o hebillas). Por otra parte, existen otros adornos que semejan un haz de varias plumas que parecen tener una función ornamental y un significado como distintivo social y religioso.

Hay otros adornos formados por líneas que al no poder interpretarse como flechas se consideran ornamentos no precisados.

Por último, existen tres ejemplares de forma extraña, cuya función es imprecisable.

El material utilizado es variado según el adorno. Puede ser de fibras vegetales, tiras de cuero y plumas, en los casos que aparece claro qué tipo de adorno es. Para otros es difícil determinar el material.

En base al formato diferenciamos tres subtipos:
- Subtipo 1 .

Son aquellos adornos representados en forma de apéndices lineales y estrechos que denominamos cintas. Se sitúan a la altura de la cintura, pudiendo figurar en uno o ambos lados. Observando las figuras constatamos que los cinturones podían estar formados por una tira o varias de fibra vegetal o cuero, cuyos extremos, una vez anudados, quedarían colgantes. Su finalidad sería utilitaria por asociarse a estuches fálicos y pantalones.

En función del número de tiras diferenciamos: la Variante a, formada por una cinta a modo de cinturón, cuyos dos extremos quedan flotantes a ambos lados del talle (Fig. 8:1) o en la parte posterior de éste (CABRÉ, 1915, lám. XXII); la Variante $b$, el cinturón está formado por dos cintas $y$, por tanto, tiene cuatro extremos que cuelgan a ambos lados de la cintura (Fig. 8: 2); la Variante c, las cintas son tres (Fig. 8: 3), aunque una de ellas sólo tiene un extremo.

- Subtipo 2.

Dentro de él englobamos dos clases de adornos. Una corresponde a los que denominamos penacho de plumas y, otra, a un conjunto de líneas más o menos gruesas diferentes de las típicas cintas de cinturón ya expuestas. Su finalidad parece ser estrictamente ornamental ya que no se asocia a ningún tipo de prenda. Se aprecia una Variante a formada por varias líneas más o menos gruesas (Fig. $8: 5)$ que en algunos casos están dibujadas toscamente. Se sitúan delante o detrás de la cintura. Podría tratarse de tiras de cuero. Una Variante $b$, compuesta por dos (Fig. 8:4), tres (Fig. 8:6) o más plumas (Fig. 8: 7) grandes, que forman un penacho colgante del talle. Por último, una Variante $\mathrm{c}$ que indica la existencia de una combinación entre las variantes a y b. El único ejemplar conocido, el jefe guerrero de Abrigo de les Dogues (Fig. 8: 4), está dotado de varias líneas, que salen un poco más arriba de la cintura, y de dos grandes plumas colgando de la misma.

\section{- Subtipo 3.}

Reunimos bajo tal subtipo aquellos adornos de difícil identificación. Su función demuestra ser esencialmente utilitaria puesto que se asocia a estuches fálicos, taparrabos, pantalones y a una falda. Se diferencian dos grupos: uno homogéneo y otro heterogéneo reflejados en: la Variante a, que designa unas protuberancias triangulares (Fig. 8: 8; Fig. 9:9) o rectangulares (Fig. 8:9), situadas en la parte posterior de la cintura, e interpretadas como lazos o cierres de cinturón; y la Variante $b$, que en- 
globa tres adornos inidentificables, dos en forma de protuberancia grande, semicircular (Fig. 8: 10) o rectangular (Fig. 9: 10), y otro formado por una serie de puntos asimétricos (Fig. 8: 11).

Respecto a la repartición geográfica, el Subtipo 1 con sus tres variantes se da como preferencia en Castellón y con su Variante a en Valencia. El Subtipo 2 en su Variante a, aparece sobre todo en Abrigo de Boro (Valencia), mientras que la Variante b en Castellón. El Subtipo 3, Variante a, se
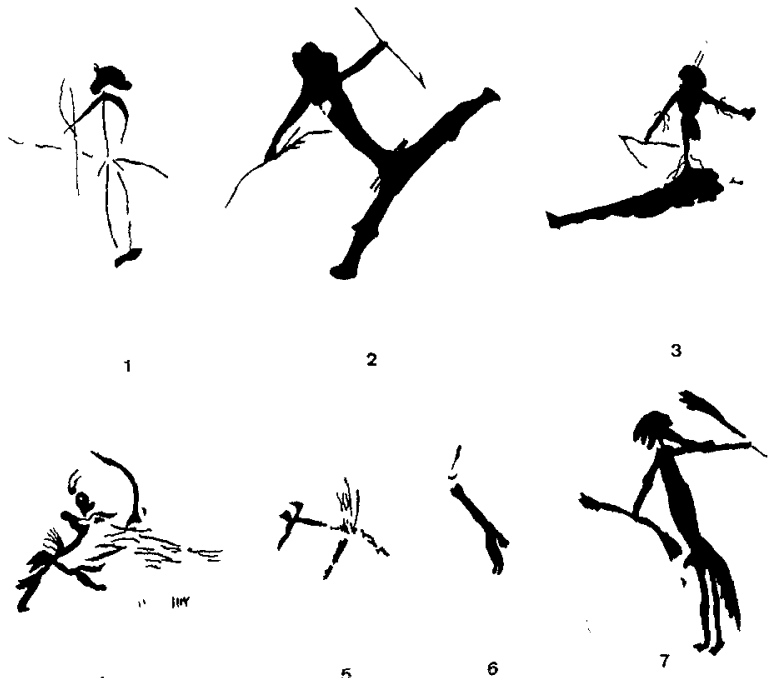

4

5
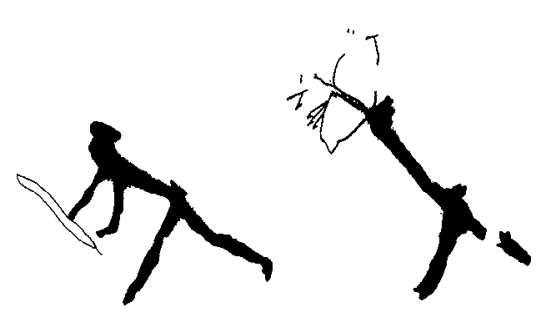

8

$$
9
$$

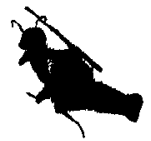

10

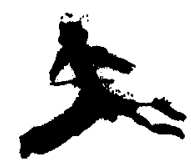

11
Fig. 8.-1, El Racó Molero (RIPOLL, 1963); 2, El Mas d'en Josep (DURÁN y PALLARES, 1915-20); 3, La Saltadora (VIÑAS, 1979-80); 4, Les Dogues (PORCAR, 1953); 5, La Mola Remigia (RIPOLL, 1963); 6-7, Cueva Remigia (PORCAR, OBERMAIER y BREUIL, 1935); 8, El Ciervo (JORDÁ y ALCÁCER, 1951); 9, La Sarga (BELTRÁN, 1974); 10-11, Els Cavalls (OBERMAIER y WERNERT, 1919). localiza en Alicante y Valencia, especialmente en Abrigo del Ciervo; la Variante b es característica de Cova dels Cavalls en Castellón y de la estación valenciana mencionada.

Los cazadores suelen estar dotados con los Subtipos 1 y 3, Variante a; los guerreros con los Subtipos 1 y 2 ; los arqueros con el Subtipo 2 (Variante b) exclusivamente: las figuras masculinas sin actividad precisada con el Subtipo 1 (Variante a);
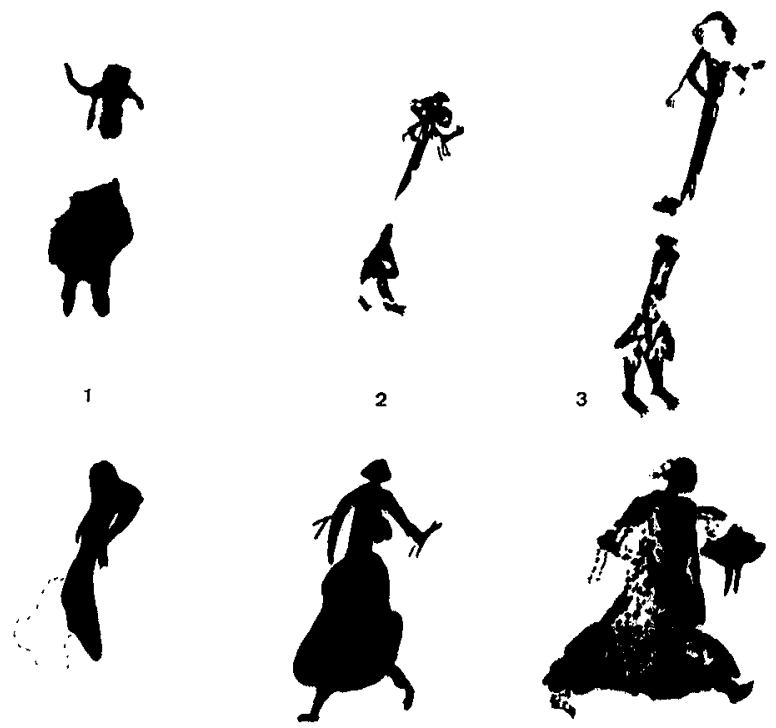

4

5 6
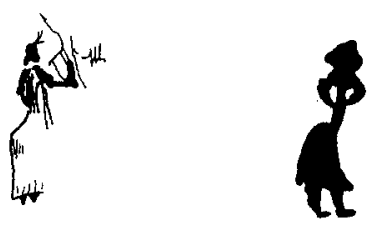

8
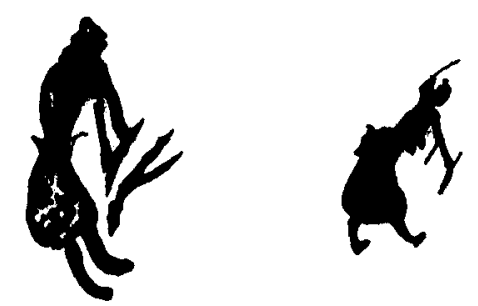

$\mathbf{g}$

10

Fig. 9.-1, Los Grajos (BELTRÁN, 1969); 2-3, La Risca (LILLO, 1978-79); 4, EI Mas d'en Josep (VINAAS, 1981); 5, 9-10, El Ciervo (JORDÁ y ALCÁCER, 1951); 6, La Pareja (JORDÁ y ALCACER, 1951); 7, La Vieja (CABRE, 1915); 8, Gadivia (MONZONIS y VIÑAS, 1980). 
las danzarinas y figuras femeninas aisladas con el Subtipo 3 (Variantes a y b).

- Cronología relativa.

Es difícilmente determinable ya que no existen paralelos muebles ni figurativos y, además, los posibles materiales utilizados -fibras vegetales y cuero- no nos aportan datos por ser atemporales.

\section{TIPO IV: ADORNOS DE PIERNAS E INDUMENTARIAS}

Al observarse las figuras humanas de nuestro arte es fácil percatarse que llevan ciertas prendas y adornos de piernas. La dificultad se presenta cuando tratamos de interpretarlos y datarlos relativamente. Debido a la variedad que presentan, diferenciamos siete subtipos y, en algunos de ellos, dos o más variantes. Es necesario indicar que las figuras femeninas tienen exclusivamente el Subtipo $6 \mathrm{y}$ las masculinas todos los demás subtipos.

- Subtipo 1.

Está constituido por aquellos adornos que consideramos ajorcas por estar situados en los tobillos. Figuran como gruesas protuberancias que resaltan sobre la línea de las piernas.

Con estos adornos se plantea el problema del material utilizado y de la cronología. Por una parte, si se considerasen como piezas líticas, sus perfiles resultarían demasiado exagerados comparados con los de brazaletes o tobilleras neolíticos y eneolíticos, aunque, quizás, existiese un deseo de exagerar el tamaño de las ajorcas por razones especiales. Por otra parte, hay quien opina que son de metal puesto que presentan, en algunos casos, perfiles angulares propios de piezas metálicas (JORDÁ, $1974,221)$. Tales perfiles se asemejan a los brazaletes y ajorcas del Tesoro de Villena cuya cronología ha sido ya dada.

En función de los perfiles diferenciamos dos clases de tobilleras: la Variante a, con una moldura curva algo elíptica (Fig. 10: 1), que suele adornar un solo tobillo; y la Variante $b$, con una (PORCAR, 1934, f. 3) o dos molduras angulares (Fig. 10: 2) que figura en uno o ambos tobillos.

\section{- Subtipo 2.}

Designa una indumentaria, conocida como taparrabo, que cubre la parte inferior del vientre. Los ejemplares registrados están formados por uno o dos retazos rectangulares, cortos, que cuelgan de la cintura cubriendo el falo y/o las nalgas. Se diferencian de los estuches fálicos por su anchu- ra y largo, puesto que estos últimos suelen ser más cortos y bastante más estrechos que los taparrabos.

Acerca del material empleado en su confección, son varias las propuestas: de piel, de corteza (BELTRÁN, 1968, 44), de tela o trenzado de cuerda (JORDÁ, 1974, 219) o bien de lino o lana. El taparrabo podía ir sujeto con un cinturón, cuyo cierre se aprecia en un antropomorfo (Fig. 10: 4).

Según la forma de la prenda se distingue: la Variante a, como una pieza rectangular corta, terminada en dos picos, que suele colgar por delante (Fig. 10:3) y por detrás (PORCAR, 1934, f. 3); la Variante $b$, como una pieza rectangular, más larga que en la anterior variante, con bordes rectos (Fig. 10: 4) y colgante por delante.

\section{- Subtipo 3.}

$\mathrm{Al}$ analizar las figuras masculinas observamos que presentan tres clases de falos. En dos de ellas, se puede distinguir el apéndice estrecho y relativamente corto, que en algunas ocasiones aparece en posición colgante y en otras erecto. En la tercera clase, los falos son grandes, anchos y colgantes. Ello nos ha llevado a pensar, por las dimensiones exageradas de dicho miembro, que pueda tratarse de un estuche fálico. Su presencia viene confirmada por la representación de un antropomorfo de Cueva de la Vieja con un cinturón que sujeta esta protección fálica (CABRÉ, 1915, lám. XXII). No obstante, no es desechable la idea de que estemos, en algunas ocasiones, ante la figuración exagerada de un falo.

En las representaciones no se puede apreciar el material con que estaban hechos. Posiblemente fuese una tira de cuero o algún tejido enrollados en torno al falo.

\section{- Subtipo 4.}

Existen dos figuras masculinas con una indumentaria que ha sido interpretada como una túnica. Son el llamado agricultor de Cinto de la Ventana (Fig. 10: 6) y uno de los participantes en el desfile procesional de Covachos de los Grajos (BELTRÁN, 1969, f. 3, n. ${ }^{\circ} 19$ ), aunque, para éste, Beltrán $(1969,25)$ considera que lleva un faldellín. La prenda consiste en una túnica, de corte y de borde rectos, que cubre el cuerpo hasta medio muslo.

\section{- Subtipo 5.}

Muchas figuras masculinas son problemáticas a la hora de determinar el tipo de adorno e indumentaria utilizado. Es el caso de las protuberancias redondeadas, de los salientes en pico y de las cintas colgantes que aparecen encima o debajo de las rodillas. 
Se han interpretado como jarreteras (WERNERT, 1917, 1), «adornos y colgajos», cintas y «rodetes» (OBERMAIER y WERNERT, 1919, 104), entendidos como ornamentos no asociados a un pantalón (BELTRÁN, 1982, 43). También han sido identificados como polainas sujetas con ligas (RIPOLL, 1961, 29; PORCAR, 1964, 164) o protectores (VIÑAS, 1981, 174). La hipótesis más generalizada considera que se trata de calzones cortos o zaragüelles (PORCAR, OBERMAIER y
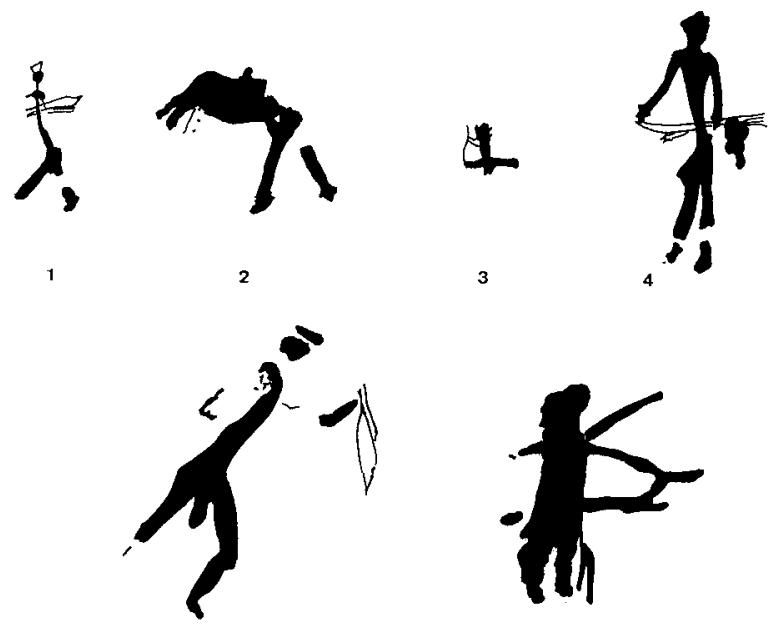

5
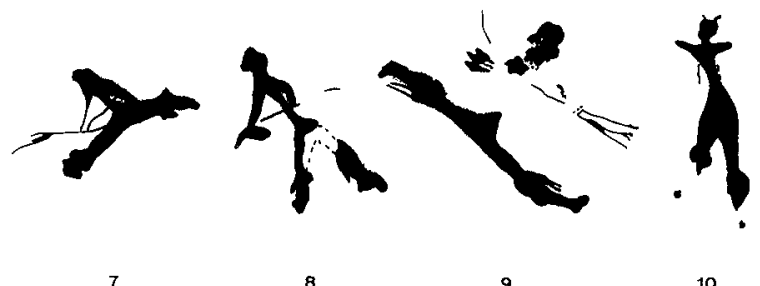
8

9

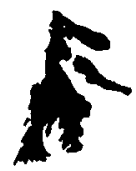

11

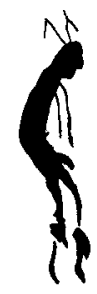

12
Fig. 10.-1, La Vieja (CABRÉ, 1915); 2 y 4, El Ciervo (JORDÁ y ALCÁCER, 1951); 3, La Mola Remigia (RIPOLL, 1963); 5, EI Queso (BREUIL, SERRANO y CABRE, 1912); 6, Cinto de la Ventana (JORDÁ y ALCÁCER, 1951); 7, El Racó de Nando (GONZÄLEZ, 1974); 8 y 11, Cueva Remigia (PORCAR, 1934; PORCAR, OBERMAIER y BREUIL, 1935); 9-10, La Saltadora (OBERMAIER y WERNERT, 1919; DURÁN y PALLARÉS, 1915-20); 11, El Polvorín (VILASECA, 1947).
BREUIL, 1935，39; RIPOLL, 1963，51; BELTRÁN, 1970, 109; PERICOT, 1974, 185; JORDÁ, 1974, 219). En efecto, parecen ser pantalones cortos, que llegan por encima o por debajo de las rodillas, y cuya parte inferior acaba de varias formas. Sin embargo, en algunas ocasiones, no hay que desechar la posibilidad de la representación de adornos.

La existencia de esta prenda se apoya en dos hechos: por una parte, cuando está presente suele faltar la representación del falo, aunque, a veces, está indicado pero de manera leve; por otra parte, comprobamos que en varias figuras se asocia a ciertos adornos de cintura (Fig. 7:2; Fig. 8: 2 y 9; Fig. 13: 5). Suponemos que los pantalones se sujetarian al talle mediante cintas, sobre todo, y otros tipos de atadura.

Se ha insinuado que fueron confeccionados con pieles (JORDÁ y ALCÁCER, 1951, 38) o con tela (JORDÁ, 1974, 219), en cuyo caso sería de lino o lana.

En función de la forma adquirida por la parte inferior de los pantalones diferenciamos: la Variante a, los bordes acaban en dos picos laterales muy marcados (Fig. 10: 7), e incluso algo colgantes (Fig. 10: 8), que posiblemente sean un convencionalismo para indicar una pernera acampanada; la Variante $b$, los bordes están ceñidos por una o más cintas, cuyos extremos quedan colgantes (Fig. 10: 9), y serían las jarreteras propiamente dichas; la Variante $c$, los bordes son protuberancias redondeadas $y$, en algunos casos, bastante ovaladas, tratándose de bajos abullonados cuya forma sería el resultado de haber doblado varias veces el borde del pantalón, aunque, también, podría tratarse de un ceñidor de forma cilíndrica.

\section{- Subtipo 6.}

Las figuras femeninas normalmente suelen vestir faldas y algún vestido. Sólo existen dos casos excepcionales en que aparecen desnudas (VIÑAS, 1981, 164, f. 242; CABRÉ, 1915, lám. XXII).

En opinión de Jordá $(1966,63)$, visten faldas o una especie de corpiño que deja los pechos descubiertos. En ninguna figura hemos observado la representación de esta última prenda. Más bien parecen tener el tronco desnudo como indican los pechos muy colgantes, resultado de no tener una sujeción.

En numerosas ocasiones, se advierte la falta de pechos, cabiendo dos posibilidades para esta ausencia; o bien estamos ante figuras infantiles, o 
bien están cubiertos por una prenda. En tal caso se trataría de vestidos, pero al no diferenciarse claramente de las faldas, los consideraremos como tales. Hasta el momento, sólo tenemos un caso indudable de vestido (Fig. 11: 5).

Existen casos curiosos de faldas como las que llevan dos mujeres de Cueva de la Vieja (Fig. 11: 12; Fig. 16: 11) decoradas a base de líneas verticales que, según Jordá $(1974,220)$, pueden corresponder a la representación de franjas de tela, cosidas unas a otras, paralelamente. Una figura de Abrigo de la Fuente del Sabuco (BELTRÁN, 1972, f. $55, \mathrm{n} .{ }^{\circ} 6$ ) presenta dibujado únicamente el contorno de la falda, apreciándose dentro de él las piernas, como si llevase un tejido transparente.

Posiblemente estuvieron hechas con pieles o con tejidos (JORDÁ, 1974, 205). Si observamos detenidamente una de las faldas amplias representadas en Abrigo del Ciervo (Fig. 11: 3), advertimos que el vuelo no responde a la rigidez de una piel de animal, sino a una materia más flexible como el tejido de lana o de lino. Las restantes faldas de corte más rígido pudieron ser de piel, aunque, también, cabe la posibilidad de que fuesen de lino o de lana.

Se diferencian tres variantes en base a la forma de la falda. La Variante a, es amplia con lados ligeramente curvados (Fig. 11:2-3) que incluso pueden llegar a dar una forma globular a la prenda (Fig. 11: 1). El largo suele ser homogéneo, llegando hasta media pierna. En algún caso, el movimiento de la figura y la amplitud de la falda implican la formación de ondas en los lados (Fig. 11: 3), pero también pueden ser dos faldas, una corta sobrepuesta a otra larga. Para el modo de sujeción, sólo conocemos un ejemplar (Fig. 9: 9) que asocia una cinta y una protuberancia triangular, situadas en el talle, con la falda. Según el borde distinguimos la Subvariante $a_{1}$, con borde recto (Fig. 11: 1), y la Subvariante $a_{2}$, con borde curvo (Fig. 11:2-3). La Variante $b$, de forma triangular y con los lados laterales rectilíneos (Fig. 11:4-8). Dentro de esta variante incluimos las llamadas faldas acampanadas, que según Beltrán (1966, 90-91) se caracterizan por terminar en dos picos laterales y que constituyen un tipo concreto de falda. Constatamos que presentan una evidente forma triangular y, por consiguiente, son semejantes a otras con dicha forma, pero figuradas con el convencionalismo de los picos mencionados. El largo es variable, pudiendo llegar hasta las rodillas, pantorrillas o tobillos. El borde puede ser recto (Subvariante $b_{1}$ ) (Fig. 11:
4-5), curvo (Subvariante $b_{2}$ ) (Fig. 11: 6) o con picos laterales (Subvariante $b_{3}$ ) agudos (Fig. 11: 7) o redondeados (Fig. 11:8). La Variante c, es estrecha y de corte recto. Por ello la llamamos «de tubo». El borde suele ser recto y el largo variable, pudiendo
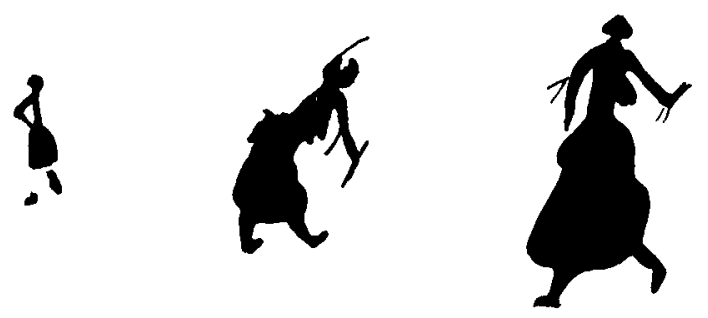

1

2

3

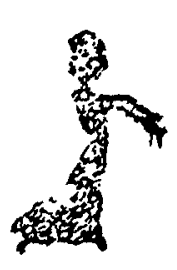

4
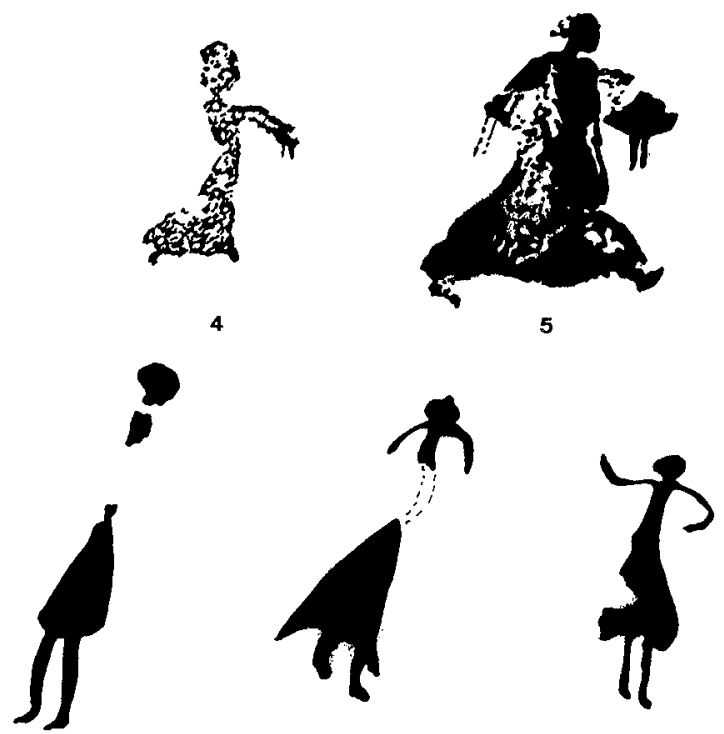

6

7

8
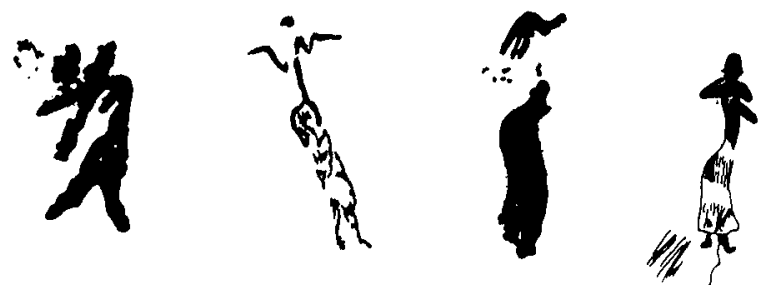

9

10

11

12

Fig. 11.-1, El Civil (OBERMAIER y WERNERT, 1919); 2-3, El Ciervo (JORDÁ y ALCẢCER, 1951); 4, L'Ermita (VIÑAS, 1981); 5, La Pareja (JORDÁ y ALCÁCER, 1951); 6-8, Los Grajos (BELTRÁN, 1969); 9, El Mas d'en Josep (VIÑAS, 1981); 10, El Polvorín (VILASECA, 1947); 11, La Madera (MONZONIS y VINAS, 1980); 12, La Vieja (CABRÉ, 1915). 
llegar hasta las rodillas (Fig. 11: 9), pantorrillas (Fig. 11: 10) o tobillos (Fig. 11: 11-12).

\section{- Subtipo 7.}

Engloba una serie de adornos de piernas un tanto extraños y difícilmente definibles. Los casos registrados son una figura sin actividad determinada (Fig. 10: 12), que según Vilaseca $(1947,24)$ «lleva sendas jarreteras... múy gruesas y puntiagudas hacia adelante y abajo», y un arquero (PORCAR, OBERMAIER y BREUIL, 1935, lám. VI, n. ${ }^{\circ} 1$ ), que en opinión de estos autores $(1935,17)$ presenta calzones cortos y de las piernas parecen destacarse cintas anchas identificadas como adornos. Consideramos que ambos ejemplares no responden a los convencionalismos dados en las variantes del Subtipo 5. Para otros casos no existe descripción de los autores. Un danzarín de Cueva Remigia (Fig. 10: 11) tiene una serie de trazos en torno a las piernas y una gran mancha triangular cubre desde la cintura hasta las rodillas. Quizá se trate de un faldellín y de una especie de polainas peludas y plumeadas. Por último, el jefe de uno de los bandos guerreros de Abrigo de les Dogues (Fig. 8: 4) lleva en cada rodilla un largo apéndice ancho; tal vez sea una cinta, aunque no corresponde al convencionalismo de la Variante b del Subtipo 5.

En todo caso, tenemos aquí ciertos adornos de piernas excepcionales, cuya definición e interpretación resultan difíciles.

La distribución geográfica del Tipo IV se establece del siguiente modo: en Castellón están presentes todos los subtipos, excepto el 3 y el 4, descollando con mayor número de ejemplares en la Variante c del Subtipo 5; en Valencia, fuera de la Variante b del Subtipo 5 y el Subtipo 7, están representados todos los subtipos, teniendo el mayor número en la Variante a del 5; en Alicante y Murcia, está ausente el Tipo IV de los adornos corporales, aunque en esta última área se da un ejemplar del Subtipo 4. Respecto al Subtipo 6, sólo femenino, se reparte de esta manera: en Castellón están las tres variantes, pero predominando la Variante c; en Valencia, también están presentes las tres y únicamente demuestra una ligera preferencia por la Variante a; en Murcia figuran, asimismo, las tres, siendo la Variante b la predominante; en Alicante, hasta el momento, sólo existe una única figura femenina, la cual lleva la Variante b. En el área murciana es donde aparece exclusivamente el convencionalismo de los picos laterales, localizándose, en concreto, en Covachos de los Grajos y Abrigo de la Risca. Este hecho lo hemos interpre- tado como un fenómeno local, aunque susceptible de estar presente en otras áreas geográficas del Arte Rupestre Levantino (Cogul).

Suelen llevar casi todos los subtipos los cazadores (excepto el 4 y el 7) y los arqueros (menos el 4). Los guerreros y las figuras sin actividad determinada están representados con los Subtipos 5 y 7 . Tanto los agricultores como los danzarines pueden figurar con el Subtipo 4. Estos últimos presentan un caso del Subtipo 7. Las danzarinas, las figuras femeninas sin actividad precisada y las mujeres aisladas visten las tres variantes del Subtipo 6, pero las primeras predominan con la Variante $b$, las segundas con la a y la $c$, y las últimas con la $b$.

\section{- Cronología relativa.}

Las ajorcas (Subtipo 1) tienen sus paralelos tipológicos dentro del mismo Arte Levantino. Efectivamente, los brazaletes presentan idénticos perfiles de modo que las variantes de ambos adornos se corresponden. Así pues, la Variante a de brazaletes cilíndricos es igual a la Variante a de ajorcas, y las variantes b y $\mathrm{c}$ de los primeros a la Variante $\mathrm{b}$ de las segundas. Por lo tanto, a efectos de cronología nos remitimos a lo expuesto en el apartado de los adornos cilíndricos de brazos.

Las faldas (Subtipo 6) han sido objeto de una datación relativa basada en paralelos figurativos. Morgan $(1921,265)$ vio una posible relación entre las faldas triangulares levantinas y las minoicomicénicas. Siguiendo esta opinión, Jordá (1966, 62-63) las paraleliza, concretamente, con la indumentaria de figuraciones plásticas del Minoico Medio de Creta, dándoles, de este modo, un origen mediterráneo. Recientemente, este autor (JORDÁ, 1983, 20-24 y Cuadro Sinóptico) fecha las faldas triangulares entre el 2500 y 2000 a. C., y las «de tubo» en dos fases: una desde el 3500 al 3000 a. C. y la otra del 2000 al 1500 a. C. En definitiva, las faldas aparecerían a partir del final del período de transición del Neolítico al Eneolítico. Ya aludimos anteriormente al problema que plantea la sistematización cronológica-cultural de Jordá. Por otra parte, existe un paralelo figurativo en las representaciones femeninas, del Período de los Cazadores Bovidianos y del Período del Caballo (HUGOT, 1974, 270 y 279), pertenecientes al Arte Rupestre del Sahara fechado a partir del Neolítico, con reservas.

También se puede intentar dar una cronología relativa aproximada a las faldas, y al mismo tiempo a los taparrabos, túnicas y pantalones, fundamentándonos en el material supuestamente utiliza- 
do para su confección. Si fuesen de piel de animal, la cronología resultaría ser muy extensa y, por consiguiente, atemporal. Si fueran realizados con tejido de lana y/o lino (ALFARO, 1984, 21-33 y 53-55), se podrían datar en la Edad del Bronce, teniendo en cuenta que la zona de distribución geográfica de las representaciones pictóricas coincide con la de hallazgos arqueológicos (pesas de telar, husos, fragmentos de tela de lino) que aseveran una actividad textil durante el período señalado. Incluso, dicha actividad es, de hecho, anterior -Eneolítica - en el área valenciana por haberse hallado materiales (pesas de telar) que la acreditan.

\section{UTILES}

\section{TIPO I: ARCOS}

El arco es un útil formado por una varilla elástica y por una cuerda o bordón. Los materiales empleados en su fabricación pueden ser madera, fina y flexible - proveniente de un árbol joven-, o dos cuernos de cabra unidos para la varilla, y fibra vegetal o tendón de animal para la cuerda. Para el tiro con arco, normalmente, se debe utilizar una placa o brazalete en el antebrazo con el fin de protegerlo del golpe del bordón al soltarse éste. En nuestros antropomorfos no hemos observado la representación de este elemento protector a menos que se consideren de tal modo los brazaletes cilíndricos. Pero ello es poco probable, ya que se sitúan en el brazo propiamente dicho. Únicamente existe un caso (Fig. 13: 11) en que el arquero lleva pulseras en ambas muñecas, las cuales pudieron servir de protectores. Sin embargo, se debe tener en cuenta que suele protegerse solamente el antebrazo izquierdo. De todos modos, consideramos extraño que los pintores levantinos no utilizasen ningún tipo de protección, sobre todo teniendo en cuenta que en las culturas materiales del Eneolítico y la Edad del Bronce del País Valenciano son abundantes los brazaletes de arqueros.

Los arcos pueden presentar, a veces, los extremos preparados, mediante una escotadura ancha y más o menos profunda, para atar la cuerda. Tal vez, tengamos la representación de esta preparación en algunos ejemplares (Fig. 12: 16; Fig. 13:4).

Asimismo, el arco puede tener en su parte central una empuñadura compuesta por àlguna fibra enrollada a la varilla. Ello permite asir más fuertemente y evitar que la mano resbale. Este elemento no se ha observado en ninguno de los arcos representados en nuestro arte.

Las posiciones que adoptan los arqueros (término generalizador empleado aquí para todos los antropomorfos que llevan arco) son variadas. Frecuentemente aparecen caminando o corriendo, transportando el arco y el haz de flechas en la mano derecha, aunque no falta algún caso en que sostengan ambos con la izquierda mientras que con la diestra tienden la cuerda al mismo tiempo que sostienen el extremo basal de la flecha.

Es curioso observar cómo los arqueros tienen ciertas costumbres, sin descartar que podría tratarse de convencionalismos, a la hora de adoptar ciertas posturas manejando el arco. Si lo llevan caminando o corriendo, suele situarse transversalmente a la altura de la cintura o del tronco. En el momento de disparar pueden estar corriendo, o bien agachados con la rodilla izquierda apoyada en el suelo o, simplemente, parados con las piernas abiertas para afianzar su fuerza y equilibrio.

Los autores del Arte Levantino utilizan el arco para cazar y guerrear. Esta arma les permite una mayor precisión y evita acercarse excesivamente a su presa, con el consiguiente peligro de espantarla o de recibir el ataque de ésta. Se debe tener en cuenta que una flecha tirada con arco alcanza una distancia de 100 a $200 \mathrm{~m}$. (ROZOY, 1978, 1012).

Utilizamos la terminología de arco simple ya que consideramos que no existen representaciones figuradas de arcos compuestos en nuestro arte. Tal consideración se basa en dos hechos: 1, el arco compuesto tiene como característica esencial ser reflejo porque al estar armado su curvatura es inversa a la curvatura que presenta en estado distendido (MONTANDON, 1934, 408); 2, se llama compuesto por ser varios los elementos que componen la varilla, bien sean dos grandes cuernos -particularmente de cabra siria (VAUDIER, $1952,575)$ - o o bien una serie de ligaduras dispuestas a lo largo de ella (MONTANDON, 1934, 407) para reforzarla. Tales características no se aprecian en nuestros arcos.

Dentro de los arcos simples levantinos hemos diferenciado dos formas en función de la curvatura:

\section{- Subtipo 1.}

Indica un arco simple convexo cuya varilla forma una curva casi semicircular (Fig. 12: 1-8). La cuerda, rectilínea, sujeta ambos extremos, pudiendo estar, en bastantes ocasiones, preparados con una escotadura (Fig. 12: 7; Fig. 13:4). De ahí que 
los cabos del bordón queden un poco más arriba del final del arco.

No se aprecian diferencias formales entre un arco convexo distendido (Fig. 12: 1-5 y 8) y uno armado (Fig. 12: 6-7). Respecto al tamaño, es siempre considerable, llegando a ser tan grande como una figura humana (Fig. 12: 2).

\section{- Subtipo 2.}

Es un arco simple biconvexo, casi siempre de grandes dimensiones, aunque también los hay pequeños, y cuyos extremos están preparados con escotaduras para insertar la cuerda. Ello se ve representado en el hecho de que los cabos del bordón se sitúan antes de finalizar los extremos de la varilla (Fig. 12: 16).

Para diferenciar los dos subtipos de arco, en posición distendida, conviene indicar que el biconvexo tiene poco espacio entre la varilla y la cuerda, siendo más estrecho que el convexo.

Este subtipo presenta ciertas características según esté distendido o armado. En función de estas posiciones distinguimos: la Variante a, el arco está distendido con la varilla que tiende a tener los extremos curvados y la parte central recta (Fig. 12:9, 11-12), aunque, a veces, puede ser cóncava (Fig. 12: 10 y 16); la Variante b, el arco está armado y la varilla presenta dos curvas convexas en ambos extremos, así como una curva cóncava en el centro (Fig. 12: 13 y 15), que en un caso falta (Fig. 12: 14). Existe un extraño arco, en Cueva Remigia (Fig. 13: 1) y Cueva de la Vieja (Fig. 12: 15), formado por dos varillas, reunidas en su parte central, que en sus extremos una queda suelta y otra sirve para sujetar la cuerda. No se sabe cuál sería el efecto de tal artilugio.

En Castellón están presentes tanto los arcos convexos como biconvexos, pero abundan más los primeros. En Valencia, también figuran los dos subtipos, aunque con un claro predominio del arco biconvexo, predominio incluso verificado en relación con otras áreas. En Alicante, existe un ejemplar del Subtipo 1 y seis del 2. En Murcia, se representan exclusivamente arcos convexos.

Respecto a las actividades, verificamos que los cazadores, los guerreros, los arqueros y algunos danzarines manejan ambos subtipos de arco. Ahora bien, matizando, los cazadores y arqueros llevan con más frecuencia arcos convexos; los guerreros parecen haber utilizado por igual los dos subtipos, y los danzarines muestran una pequeña preferencia por el arco biconvexo.

- Cronología relativa.
Restos materiales de arcos convexos han sido encontrados en Holmegaard (Seeland, Dinamarca) -600O a. C. - y en Wiss (cuenca del Petchora) -entre el 6100 y 5100 a. C.- (JORDÁ, 1980, 89). Más reciente es el arco entero de 1,30 m. descubierto en el poblado de Les Baigneurs (Charavines, Isére, Francia), perteneciente a la Civilización SaôneRhône, y datado absolutamente en el 2700 a. C. (BOCQUET et HOUOT, 1982, 18).

Paralelos figurativos tenemos en las pinturas de dos santuarios de Çatal Hüyük (Anatolia), uno del Nivel VII -62OO-6O5O \pm 100 a. C.- (JORDÁ,
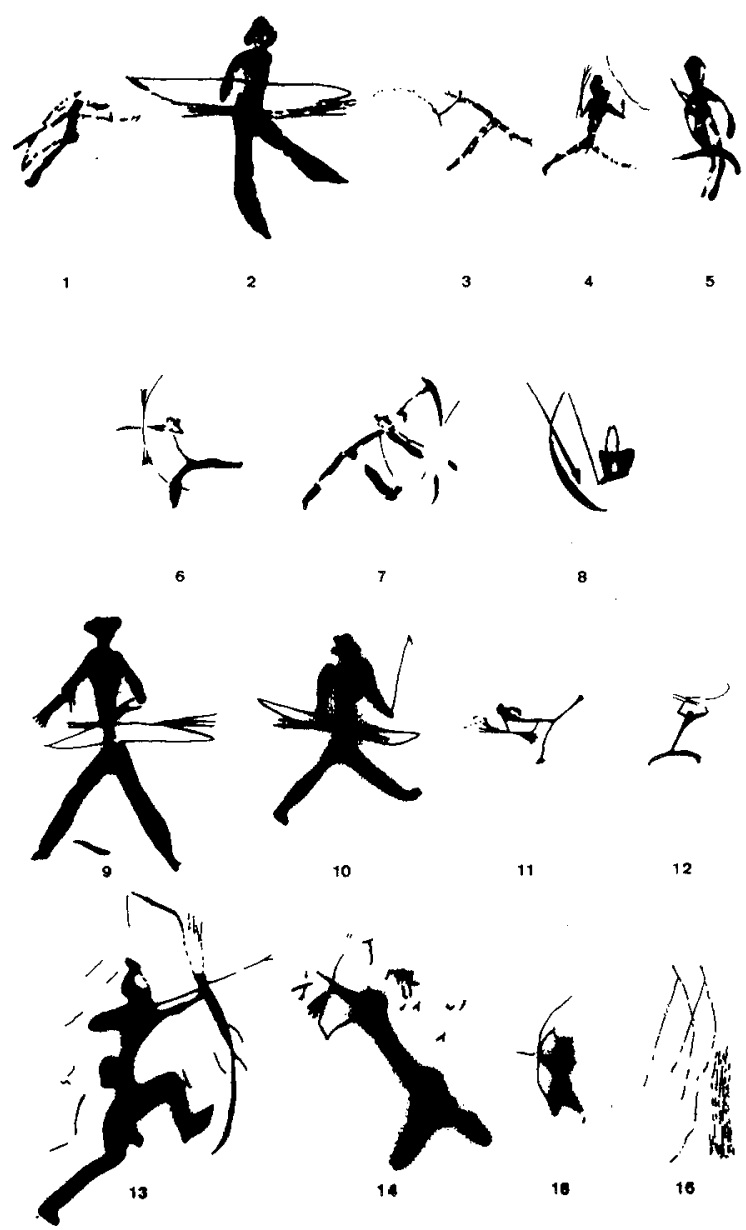

10

11

12
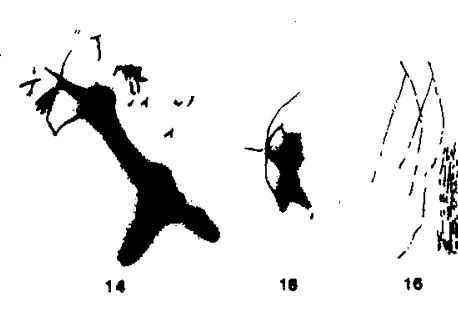

Fig. 12.-1, 3-4, La Mola Remigia (RIPOLL, 1963); 2, La Pareja (JORDÁ y ALCÁCER, 1951); 5, El Polvorín (VILASECA, 1947); 6, 8 y 13, Cueva Remigia (PORCAR, OBERMAIER y BREUIL, 1935; ESTEVE, 1974; PORCAR, 1934); 9-10, El Ciervo (JORDÁ y ALCÁCER, 1951); 11, Els Cavalls (OBERMAIER y WERNERT, 1919); 12, El Civil (OBERMAIER y WERNERT, 1919); 14, La Sarga (BELTRÁN, 1974); 15, La Vieja (CABRÉ, 1915); 16, La Saltadora (VINAS, 1979-80). 
$1980,88, \mathrm{f} .1: 1-2)$ y otro del Nivel III $-5790-5750$ a. C.- (MELLAART, 1971, 52, 133-134, f. 6163). En la Península Ibérica existen en el Arte Rupestre Esquemático (ACOSTA, 1968, 152-153, f. 48-49 y Mapa 22) y en las estelas decoradas del Suroeste (ALMAGRO BASCH, 1966, lám. V, XXV; VARELA y PINHO, 1977, 189, f. 8 c; 193 y 197).

Los paralelos muebles de los arcos biconvexos proceden del yacimiento epipaleolítico final del Wiss y de la estación arqueológica de Braband (Dinamarca), perteneciente al Erteböllense de transición con elementos cerámicos (JORDÁ, 1980, 89). Respecto a los paralelos figurativos, señalamos la existencia de arcos muy parecidos, tanto distendidos como armados, en el arte rupestre del Tassili (LECLANT et HUARD, s. a., 167, f. 45: 1-4) y, con la primera posición, en las pinturas de un santuario del Nivel VIII de Çatal Hüyük datado en 6280/6200 a. C. (MELLAART, 1971, 52, 94, f. 46). Asimismo, los encontramos en las estelas decoradas del Suroeste peninsular (ALMAGRO BASCH, 1966, lám. III y XXI; ALMAGRO GORBEA, 1977, lám. XIX, 4; CHAVES y DE LA BANDERA, 1982, f. 3). Es interesante indicar la ausencia de este subtipo de arco en el Arte Esquemático de la Península Ibérica.

Fundamentándonos en las figuraciones y hallazgos materiales de las diversas culturas prehistóricas mencionadas, comprobamos que los arcos convexos y biconvexos tienen idéntica cronología $y$, consecuentemente, son sincrónicos.

\section{TIPO II: FLECHAS.}

En otro lugar abordábamos el estudio de este útil, y nuestras conclusiones al respecto, nos remitían a la clarificación de la cuestión de los extremos foliáceos de las flechas, a la clasificación de las puntas y una aproximación cronológica-cultural.

Todo parece indicar, en base a la tecnología de las flechas (ROZOY, 1978, 1009-1012 y 1017), que los extremos foliáceos representan puntas y no emplumaduras. Estas últimas tienen su figuración en dos o tres apéndices filiformes, situados en la base del astil (Fig. 13: 4), que reflejan perfectamente el convencionalismo utilizado para representar plumas.

En función de la forma de las puntas distinguimos cuatro subtipos:

- Subtipo 1.
El extremo del astil presenta una forma recta (Fig. 13: 1-3) y probablemente fue aguzado y endurecido al fuego.

\section{- Subtipo 2.}

Designa una flecha cuya punta tiene forma foliácea (Fig. 13: 4 y 6) o con tendencia romboidal (Fig. 13: 5).

- Subtipo 3.

Indica una punta de flecha con forma triangular (Fig. 13: 7-9).

\section{- Subtipo 4.}

Señala una punta de flecha en forma de ángulo agudo, o sea, que desde el mismo extremo del astil surge un trazo oblicuo y recto (Fig. 13: 9-11). La hemos denominado punta con gancho, aunque no se puede apreciar si se trata de un apéndice incorporado al extremo del vástago. Otros autores la describen como una punta con aleta lateral (APARICIO, 1980, 79), un diente de arpón o anzuelo (JORDÁ, 1974, 213; 1980, 93) y un arponcillo angular (BELTRÁN, 1982, 54).

La distribución geográfica se verifica del siguiente modo: en Castellón, están representados los cuatro subtipos siendo cla ramente predominante el Subtipo 1. Respecto a otras áreas, sobresale el Subtipo 2 con el mayor número de ejemplares. Destacan las asociaciones en una misma estación rupestre de los Subtipos 1, 2 y 3 -Cueva Remigia- y de los dos primeros - Cingle de la Mola Remigia, Abrigo de les Dogues, Coves del Civil, Cova dels Cavalls, Cova Alta del Llidoner, Coves de la Saltadora y Abrigo del Racó de Nando-. En Valencia, figuran los Subtipos 1, 2 y 4, correspondiendo al primero la mayoría de ejemplares. En relación con otras áreas, predominan el $1 \mathrm{y}$ el 4 . Los tres subtipos aparecen asociados en Cueva de la Vieja; el 1 y el 2 en Cuevas de la Araña y Abrigo de Boro; el 1 y el 4 en Abrigo del Ciervo. En Alicante, sólo se conocen dos casos del Subtipo 2 y uno del Subtipo 4, asociándose ambos en Covachos de la Sarga. En Murcia, únicamente se ha localizado un ejemplar del Subtipo 2 en Abrigo de la Fuente del Sabuco. En esta área, la excesiva degradación de las pinturas no permite apreciar las puntas de flecha. Las flechas son utilizadas por los cazadores, guerreros, arqueros, danzarines y figuras sin actividad precisada. Los primeros sobresalen con los Subtipos 1 y 4, pero también figuran con el Subtipo 2. Los guerreros presentan los mismos subtipos, predominando con el 1 y el 2 . Los arqueros utilizan los Subtipos 1, 2 y 4, destacando el primero en número de ejemplares. Los danzari- 
nes manejan exclusivamente los Subtipos 1 y $\mathbf{3}$, siendo el primero preponderante. Las figuras sin actividad determinada llevan flechas con los Subtipos 2 y 3 de puntas, sobresaliendo en el primero.

Al igual que ocurría con los arcos, las flechas siempre aparecen en posiciones convencionales. Pueden estar: en posición de disparo, depositadas en el suelo - verticalmente u horizontalmente-, formando un haz sostenido junto con el arco, bien transversalmente a la altura de la cintura, bien en posición de disparo; también, el arquero (término generalizador) puede sujetar el manojo con una mano, llevarlo dentro de un carcaj o colgado de la espalda. No faltan los casos en que se representa una sola flecha sostenida verticalmente ante la figura humana o enarbolada. Asimismo, suelen figurar en panoplias, agrupadas paralelamente o en haces. Únicamente conocemos un caso donde está pintada una sola flecha (Fig. 13: 8).

- Cronología relativa.

El intento de aproximación al encuadre cronológico-cultural se basa en los hallazgos materiales y las figuraciones de puntas de flecha que presentan una forma semejante a nuestros subtipos. Así, al Subtipo 1 corresponden paralelos muebles desde el Epipaleolítico -yacimiento de Holmegaard, Wiss y Stellemoor (ROZOY, 1978, 1017) - , y figurativos hasta la Primera Edad del Hierro -en alguna estela del Suroeste (ALMAGRO BASCH, 1966, lám. XXVIII) fechada a fines del S. IX y en el S. VIII a. C. (VARELA y PINHO, 1977, 197)-. Los subtipos 2 y 3 son similares a las puntas de sílex foliáceas/romboidales y con aletas y pedúnculo datadas, las primeras, a partir de los inicios del IV Milenio a. C., y, las segundas, desde el Neolítico Final, Ilegando ambas formas, pero con paralelos metálicos, hasta el Bronce Final e incluso, para el Subtipo 3 en paralelos figurativos -algunas estelas decoradas del Suroeste (ALMAGRO BASCH, 1966, lám. III y XXI; CHAVES y DE LA BANDERA, 1982, f. 3) fechadas entre el S. X y el S. VIII a. C. (VARELA y PINHO, 1977, 196-197)—, hasta la Primera Edad del Hierro. El Subtipo 4 no ha podido ser datado por no existir hallazgos materiales claramente parecidos y por tener un paralelo figurativo de cronología insegura - estación rupestre de Abka (Nubia) adscrita al arte rupestre sahariano (LECLANT et HUARD, s. a., 155).

Los datos presentados indican que existen, al menos, dos subtipos de puntas de flecha cuyos paralelos muebles se encuentran en un amplio perío- do cronológico. Por una parte, las puntas foliáceas/romboidales aparecen a partir del inicio del IV Milenio y, por otra, las de aletas y pedúnculo desde fines del Neolítico. Ambas formas de punta siguen encontrándose hasta finales del II Milenio a. C.

Al estudiar la cultura material del Eneolítico, se aprecia que la técnica de la talla del sílex alcanza una perfección cuyo reflejo se observa particularmente en las puntas de flecha. Respecto a ellas es
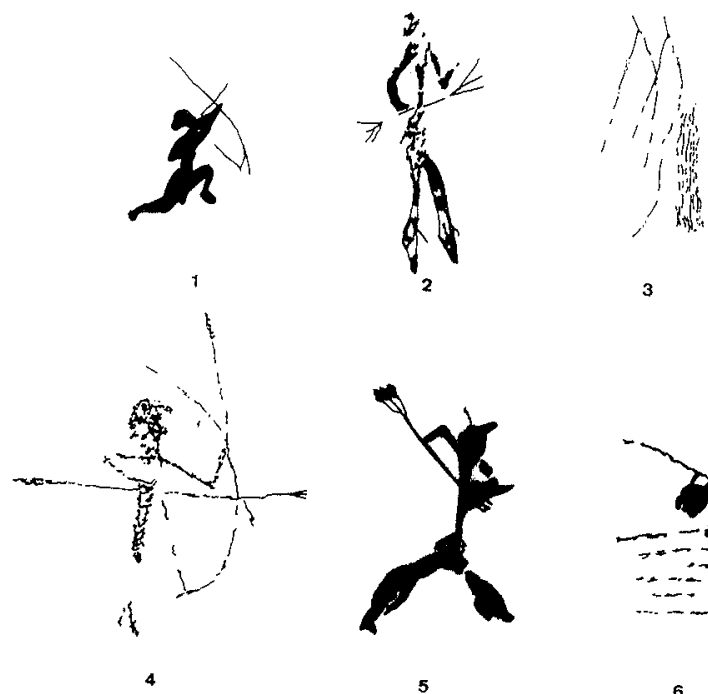

3
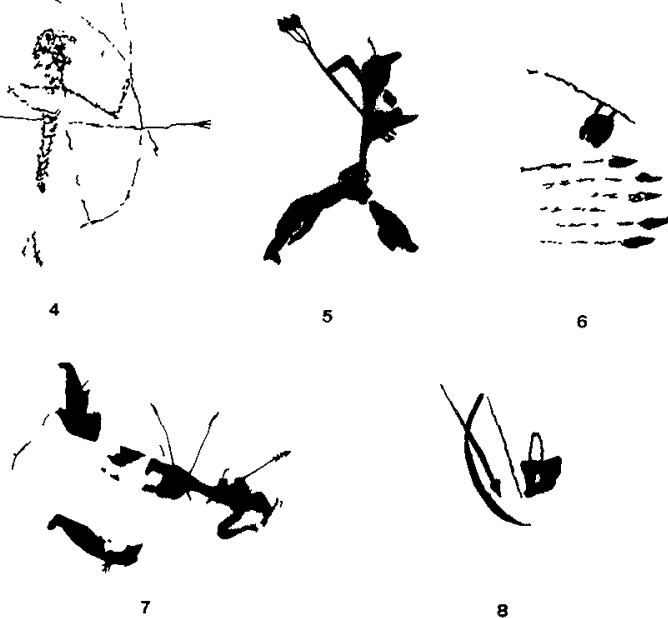

5

6

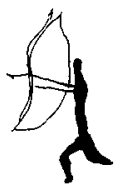

9

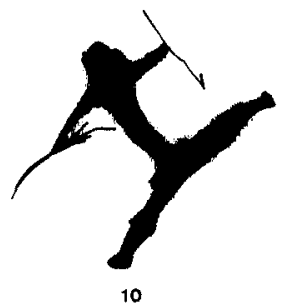

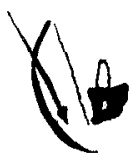

8

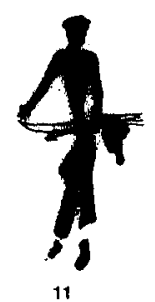

Fig. 13.-1, 7-8, Cueva Remigia (PORCAR, 1934; PORCAR, OBERMAIER y BREUIL, 1935; ESTEVE, 1974); 2 , El Polvorín (VILASECA, 1947); 3 y 5, La Saltadora (VINAS, 1979-80; OBERMAIER y WERNERT, 1919); 4, La Araña (JORDÁ, 1974); 6, La Mola Remigia (RIPOLL, 1963); 9, La Vieja (CABRE, 1915); 10, El Mas d'en Josep (DURÁN y PALLARÉS, 1915-20); 11, El Ciervo (JORDÁ y ALCÁCER, 1951). 
destacable un hecho: suelen ser abundantes en los enterramientos múltiples y en los asentamientos.

Interesa indicar que las puntas eneolíticas y las representadas en el Arte Rupestre Levantino coinciden en dos puntos: las formas son semejantes y la frecuencia de aparición es cuantitativamente importante.

Teniendo en cuenta estas coincidencias, cabría la posibilidad de considerar que muchas de las puntas levantinas sean representaciones de las eneolíticas.

\section{TIPO III: RECIPIENTES.}

Las figuraciones de recipientes plantean ciertos problemas a la hora de apreciar el posible material empleado en su fabricación y si, algunas de ellas, deben considerarse como recipientes. Un recolector de Cingle de la Mola Remigia (RIPOLL, 1963, lám. IV , n. $\left.{ }^{\circ} 13\right)$, según este autor $(1963,17)$, lleva un «faldellín» que se podría interpretar como una bolsa colgada de la cintura puesto que otro recolector de Cingle del Mas d'en Josep (Fig. 14: 6) presenta una en la espalda. Ahora bien, por la posición del objeto en la primera figura, consideramos que se trata de un taparrabo. La mujer con un vestido amplio de Abrigo de la Pareja (Fig. 11: 5), en opinión de Jordá y Alcácer $(1951,25)$, tiene una cesta colgada del brazo izquierdo. Por nuestra parte observamos que dicha figura tiene los brazos en jarras y recubiertos por mangas muy anchas de donde penden dos cintas de cada una. Una danzarina de Covachos de los Grajos (BELTRÂN, 1969, f. $3, n .^{\circ} 41$ ) está representada con una mancha circular a escasa distancia de su mano izquierda. Tal vez se trate de un recipiente esférico, pero no presenta ningún indicio de borde ni elemento de sujeción que lo determinen como tal. Por último, un cazador de Cueva del Polvorín (Fig. 15:6) sostiene una «cesta o cubo» con tapadera, según Vilaseca $(1947,31)$. Bien podría ser la mano cerrada en puño, que luce en la muñeca una pulsera con perfil angular. No obstante, esta interpretación es poco probable puesto que la mano resultaría demasiado grande en proporción con el cuerpo del personaje. Además, la otra mano apenas está siquiera insinuada.

Cuestiones ineludibles son el hipotético material utilizado y la función específica de estos recipientes. Ambas cuestiones dependen principalmente de la actividad en que se emplean dichos objetos.
Los carcajes, representados en cazadores, arqueros y guerreros, requieren un material resistente y ligero, para transportar las flechas, como el cuero, el mimbre (ESTEVE, 1974, 11) y la madera. Los pequeños recipientes, con o sin asas, llevados por cazadores, guerreros, recolectores y figuras sin actividad precisada, así como los representados en panoplias, debieron contener venenos, miel, colores y algún que otro sólido y líquido. En el caso que fuesen para líquidos serían de cuero, de esparto -revestido internamente de alguna materia impermeable- o de madera (ESTEVE, 1974, 11). Incluso, en algún caso, podría tratarse de vasijas de barro, a veces envueltas en una especie de bolsa de piel, esparto o lana (MESADO, 1981, 300). Si fuesen para transportar sólidos serían, también, de cuero, de esparto, sin necesidad de impermeabilizarlos por dentro. Las bolsas están representadas en cazadores y recolectores y, quizá, fueron de cuero curtido, sirviendo para guardar venenos, miel y algún otro producto necesario para ellos.

Consecuencia de todo lo expuesto es la diferenciación de tres subtipos:

- Subtipo 1.

El carcaj es un útil empleado para transportar flechas. Su forma, en corcordancia con su función, es de tendencia rectangular, y posiblemente cilíndrica, y bastante alargada.

Por lo que se desprende de los escasos carcajes representados en el Arte Rupestre Levantino, es un objeto poco utilizado por sus autores. Suelen llevarlos en la mano en posición transversal al tronco, pudiendo tener un asa en medio (Fig. 14: 1), colgados de la espalda (Fig. 14: 3), mediante una bandolera (Fig. 14: 2), y de la cintura (Fig. 14:4).

En función de la forma se diferencia: la Variante a, rectangular cilíndrica alargada con base plana (Subvariante $a_{1}$, Fig. 14: 1-3) o bifurcada (Subvariante $a_{2}$, Fig. 14: 4); la Variante b, elipsoidal vertical (Fig. 14: 5), cuyo único ejemplar tiene la trama del tejido representada.

- Subtipo 2.

Las bolsas son recipientes cuya característica principal es la carencia de asa. Suelen presentar una variedad de formas hasta el punto de no haber dos ejemplares iguales.

En la mayoría de las ocasiones, las figuras humanas las llevan colgadas de la espalda (Fig. 14: 6 y 9), pero, también, hay algún caso donde aparecen en la mano (Fig. 14: 7) o colgadas del hombro por medio de una bandolera (Fig. 14: 10). 
Se han agrupado, a grosso modo, en cuatro variantes basadas en una morfología aproximadamente parecida. La Variante a, con forma elipsoidal vertical (Fig. 14: 6); la Variante b, elipsoidal horizontal (Fig. 14: 8); la Variante c, con tendencia cilíndrica o rectangular alargada y base estriada (Fig. 14: 9), y la Variante d, sin forma aparente (deforme) (Fig. 14: 10).

\section{- Subtipo 3.}

Los cestos se definen por la presencia de un asa y por las formas geométricas definidas. Sólo existen dos ejemplares (Fig. 15: 1-2) que no llevan el aludido elemento de sujeción, pero su morfología
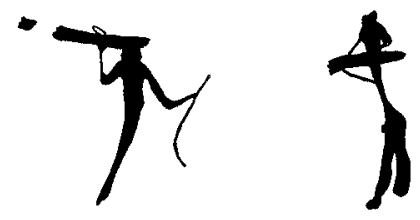

2
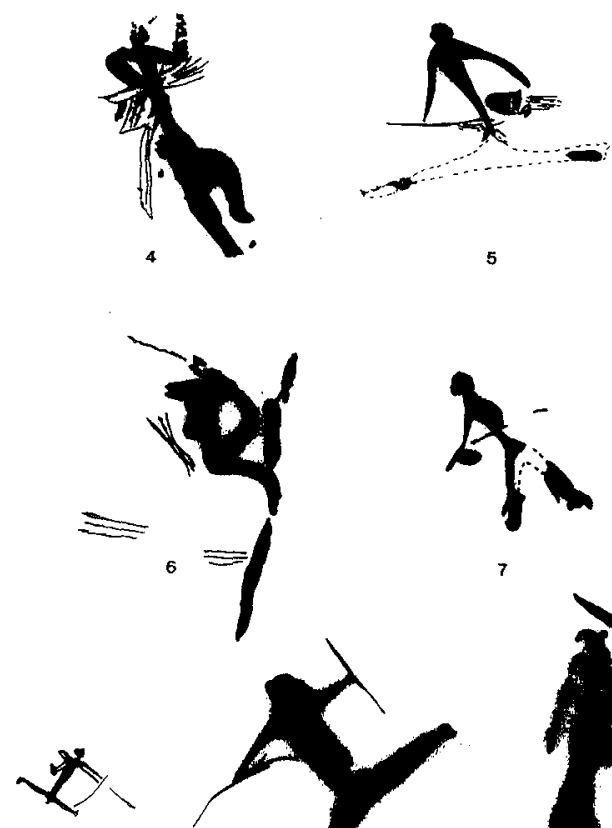

8
5

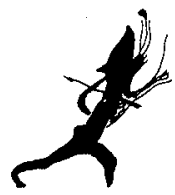

3

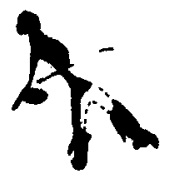

7

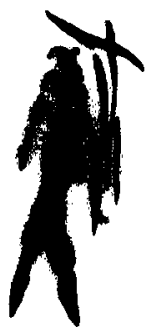

10
Fig. 14.-1-2, El Civil (OBERMAIER Y WERNERT, 1919); 3, La Vieja (CABRÉ, 1915); 4, Benirrama (ASQUERINO y C. E. C., 1981); 5, 7-8, Cueva Remigia (PORCAR, OBERMAIER y BREUIL, 1935; PORCAR, 1934); 6 y 9, El Mas d'en Josep (VIÑAS, 1981; OBERMAIER y WERNERT, 1919); 10, La Mola Remigia (PORCAR, 1943). es perfectamente relacionable con las formas de otros cestos.

Las figuras humanas suelen transportar los cestos cogidos por el asa (Fig. 15: 6) y colgados del brazo (Fig. 15: 10). Asimismo, aparecen junto a antropomorfos (Fig. 15: 1-2). Es destacable que la mayoría de las veces están representados en panoplias asociados a bastones, arcos, flechas y carcajes (Fig. 15: 4, 7-9 y 12). Igualmente pueden estar solos (Fig. 15: 5 y 11).

En base a la forma hemos establecido cinco variantes: la Variante a, elipsoidal vertical (Fig. 15: 1-4) sin asa (Fig. 15: 1-2) o con asa vertical (Fig. 15: 3) u horizontal (Fig. 15:4) y en un caso se observa la trama del tejido de fibras vegetales (Fig. 15: 2); la Variante b, con tendencia esférica (Fig. 15: 5-7), puede tener un cuello cilíndrico y asa vertical (Fig. 15: 7), tres apéndices verticales ondulados como elemento de sujeción (Fig. 15: 5) o una posible tapadera (Fig. 15: 6), y un único ejemplar aparece con la trama del tejido representada (Fig. 15: 5): la Variante $c$, cilíndrica con fondo plano (Fig. 15: 8-10), pudiendo ser más ancha que larga (Fig. 15: 8-9) o viceversa (Fig. 15:10), con asas verticales (Fig. 15:9), y en algún caso se aprecia la trama del tejido (Fig. 15: 9); la Variante d, semiesférica y con asa vertical (Fig. 15: 11); la Variante e, se caracteriza por ser recipientes geminados con forma troncocónica invertida y con asa vertical (Fig. 15: 12; Fig. 13: 8).

En Castellón observamos la presencia de los tres subtipos, pero prevalece el Subtipo 2 en número. No obstante, no debemos olvidar que la totalidad de las panoplias, donde figuran los Subtipos 1 y 3, se hallan en esta área. En Valencia están representados los tres subtipos, con un ejemplar cada uno. En Alicante se dan los Subtipos 1 y 2, con, respectivamente, dos ejemplares y uno. En Murcia, los recipientes están totalmente ausentes.

Los cazadores llevan los tres subtipos, predominando sobre todo el 2. Los guerreros figuran con los Subtipos 1 y $3, y$ los recolectores con el 2 y el 3. Por último, las figuras sin actividad determinada, una femenina y otra masculina, transportan el Subtipo 3. Conviene señalar que las bolsas suelen asociarse a cazadores y, por ello, tendrían una función relacionada con la caza. No se puede decir lo mismo de los carcajes con respecto a los guerreros puesto que los cuatro ejemplares adjudicados a éstos pertenecen a una misma escena bélica de Coves del Civil. Por consiguiente, es un hecho local y no generalizable al ámbito geográfico estudiado. 
- Cronología relativa.

Los datos que nos aportan una datación relativa son escasos. Por una parte, se constata la falta de paralelos figurativos. En cuanto a los paralelos muebles, tenemos los cestos de esparto de Cueva de los Murciélagos (Albuñol, Granada) (GÓNGORA, 1868, 35) que presentan formas muy parecidas a algunos de los representados en nuestro arte. $\mathrm{Pa}$ ra este yacimiento se ha propuesto una cronología del Neolítico Final o bien del Eneolítico. También, cabe la posibilidad de que algún que otro cesto levantino sea la plasmación de vasijas cerámicas del Neolítico valenciano.

Por otra parte, se puede intentar hallar una cronología relativa a través de los hipotéticos materiales utilizados en la confección de los recipientes. Probablemente emplearon el cuero, pero su
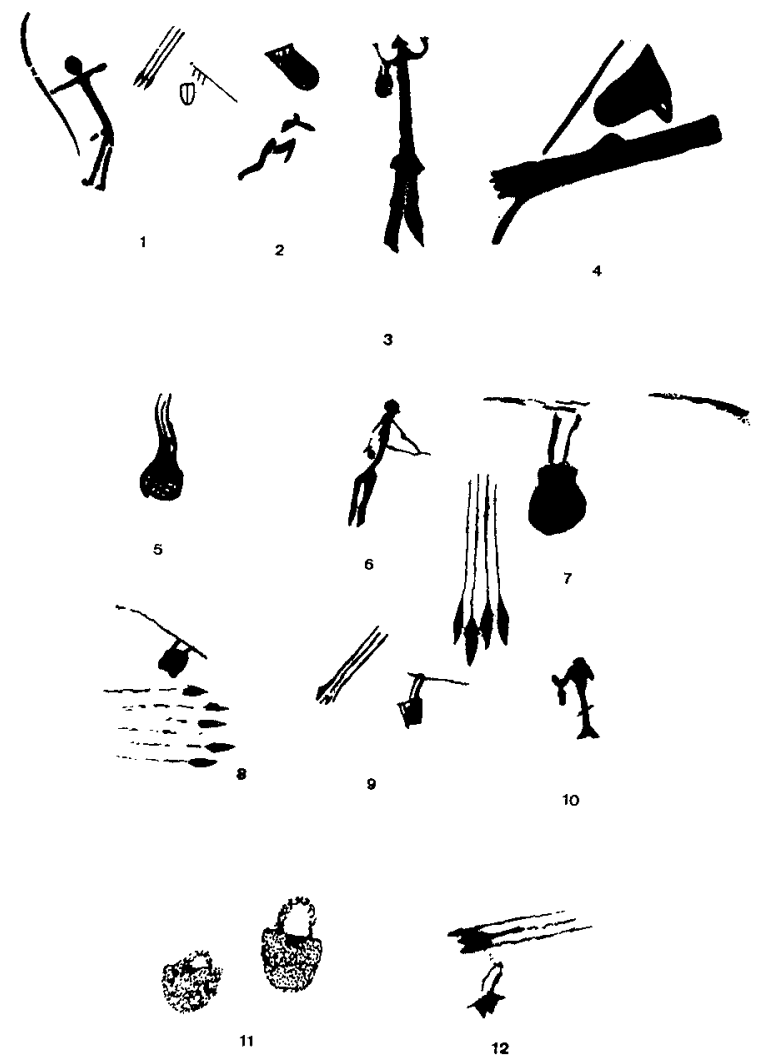

Fig. 15.-1, 8-9, 12, La Mola Remigia (RIPOLL, 1963; ESTEVE, 1974; PORCAR, 1943); 2, 5 y 7 , Cueva Remigia (PORCAR, OBERMAIER y BREUIL, 1935; PORCAR, 1945; ESTEVE, 1974); 3, Benirrama (ASQUERINO y C. E. C., 1981); 4, La Saltadora (OBERMAIER y WERNERT, 1919); 6, El Polvorín (VILASECA, 1947); 10, El Civil (OBERMAIER y WERNERT, 1919); 11, El Racó Molero (RIPOLL, 1963). utilización se dio en todos los tiempos prehistóricos y no indica una datación concreta. Por la presencia de un carcaj y tres cestos con la trama del tejido señalada, se supone que fueron hechos con fibras vegetales. El esparto tejido es el único que ha dejado evidencias arqueológicas (ALFARO, 1984, 62-67) fechables en el Eneolítico (PLA, 1972, 327; MUÑOZ, 1982, 16; 1983, 7) y Edad del Bronce (PLA, 1972, 329; NAVARRO, 1983, 40), aunque es muy probable que su aparición fuese anterior.

\section{TIPO IV: UTILES VARIOS}

En el Arte Rupestre Levantino existen una serie de figuraciones excepcionales cuya problemática radica en establecer su función, el material empleado en su fabricación y su interpretación. Ante estas características, los hemos denominado «útiles varios» y dentro de ellos distinguimos cinco grupos y de cada uno exponemos la dispersión geográfica, la relación con las actividades y la cronología relativa, en el caso de haberla.

\section{- Grupo A.}

Indica un conjunto de representaciones lineales asociadas a figuras humanas (Fig. 16: 1-2 y 4-5) o aisladas (Fig. 16: 3 y 6). El rasgo común de todas ellas parece estar en la función que tienen. Los antropomorfos las utilizan para sujetar o sujetarse como en el caso de los recolectores.

Diferenciamos cuatro subgrupos. El Subgrupo 1, son trazos filiformes (Fig. 16: 2) o anchos (Fig. 16: 1) que tienden a la verticalidad. Normalmente puede haber un trazo o tres casi paralelos. Asimismo, existe una representación aislada en Cueva del Polvorín con dos trazos verticales unidos en su parte inferior por dos horizontales (Fig. 16: 3). Quizá, los trazos más finos representen cuerdas mientras que los gruesos, ramas o troncos. Están representados en recolectores de Cueva Remigia, Cingle de la Mola Remigia, Cingle del Mas d'en Josep, Cingle de l'Ermita, Cuevas de la Araña y Cueva de la Vieja.

El Subgrupo 2, se trata de una representación lineal filiforme (Fig. 16: 4). Únicamente aparece en un cazador (por llevar armas) de Cueva del Polvorín que sujeta con ella un cuadrúpedo. Se interpreta como una larga cuerda utilizada a modo de lazo (VILASECA, 1947, 20). El Subgrupo 3, es otra representación filiforme (Fig. 16: 5) que figura en el caballo montado por el jinete con casco de Cingle de la Mola Remigia. Es posible que nos hallemos ante una brida. Respecto a la monta del caballo 
con bridas, Almagro Gorbea $(1977,121-122)$ señala que se trata de un fenómeno cultural aparecido a finales de los Campos de Urnas y opina que esta figura se debe fechar a partir del S. VIII avanzado. Ya expusimos anterioremente nuestra opinión sobre este particular. El Subgrupo 4, indica una serie de trazos filiformes entrecruzados formando una estructura más o menos compleja (Fig. 16: 6). Se han interpretado como trampas (JORDÁ y ALCÁCER, 1951, 13; BLASCO, 1974, 51). Figuran en Abrigo del Ciervo y Cueva de la Vieja.

La cronología relativa para los subgrupos 1, 2 y 4 se puede establecer suponiendo que las cuerdas eran trenzadas a base de fibras vegetales. Hasta el momento, sólo nos queda constancia arqueológica del trenzado del esparto para cuerdas en yacimientos eneolíticos - Cueva de los Murciélagos de Albuñol y Villafilomena (Villarreal, Castellón) (ALFARO, 1984, 188) - y poblados de la Edad del Bronce - por ej., Cabezo Redondo (Villena) (PLA, 1972, 329), Lugarico Viejo y El Argar (Antas, Almería) (LULL, 1983, 247 y 254)-. Sin embargo, es muy posible que la aparición del tejido de esparto sea anterior.

\section{- Grupo B.}

Abarca una serie de útiles en función de su interpretación y no de su forma. De ahí que se denominen «elementos agrícolas». Se trata de palos de cavar (Fig. 16: 7) (JORDÁ y ALCÁCER, 1951, 16), una laya y un arado (Fig. 16: 8) (JORDÁ, 1971, 244-245).

Los palos de cavar están representados en dos danzarinas de Abrigo del Ciervo y en un danzarín de Cingle de la Mola Remigia. La cronología relativa se establece a partir del Neolítico, en base a la presencia de un esferoide de piedra perforado, procedente de Cova de la Sarsa, que serviría de contrapeso a un palo de cavar (JORDÁ, 1971, 241).

La laya y el arado figuran en un antropomorfo de Cinto de la Ventana. Es una interpretación dada por Jordá $(1971,246-247)$ que cabe cuestionarse. El arado resulta extraño ya que le sobran algunos trazos para ser tal. Asimismo, la laya es de factura rara por tener un mango demasiado estrecho con respecto a la horquilla. Podría tratarse de representaciones de otros útiles que por el momento nos es difícil discernir.

\section{- Grupo C.}

Engloba varias figuraciones que interpretamos como «elementos de índole religiosa». Por una parte, son tres varas con plumas (Fig. 16:9) y un objeto indeterminado (Fig. 16: 12) de Cueva Remi- gia. Por otra parte, hay dos figuritas, una antropomorfa de Cueva del Queso (Fig. 16:10) y otra zoomorfa de Cueva de la Vieja (Fig. 16: 11), interpretadas como idolillos.

Se han considerado como «elementos de índole religiosa» por asociarse, en unos casos, a figuras humanas danzantes que, posiblemente, estén realizando un tipo de actividad religiosa, ejemplo de los dos danzarines con máscaras de pájaro de Cueva Remigia.

\section{- Grupo D.}

Agrupa ciertos útiles interpretados como armas por estar relacionados en su mayor parte con guerreros y cazadores.

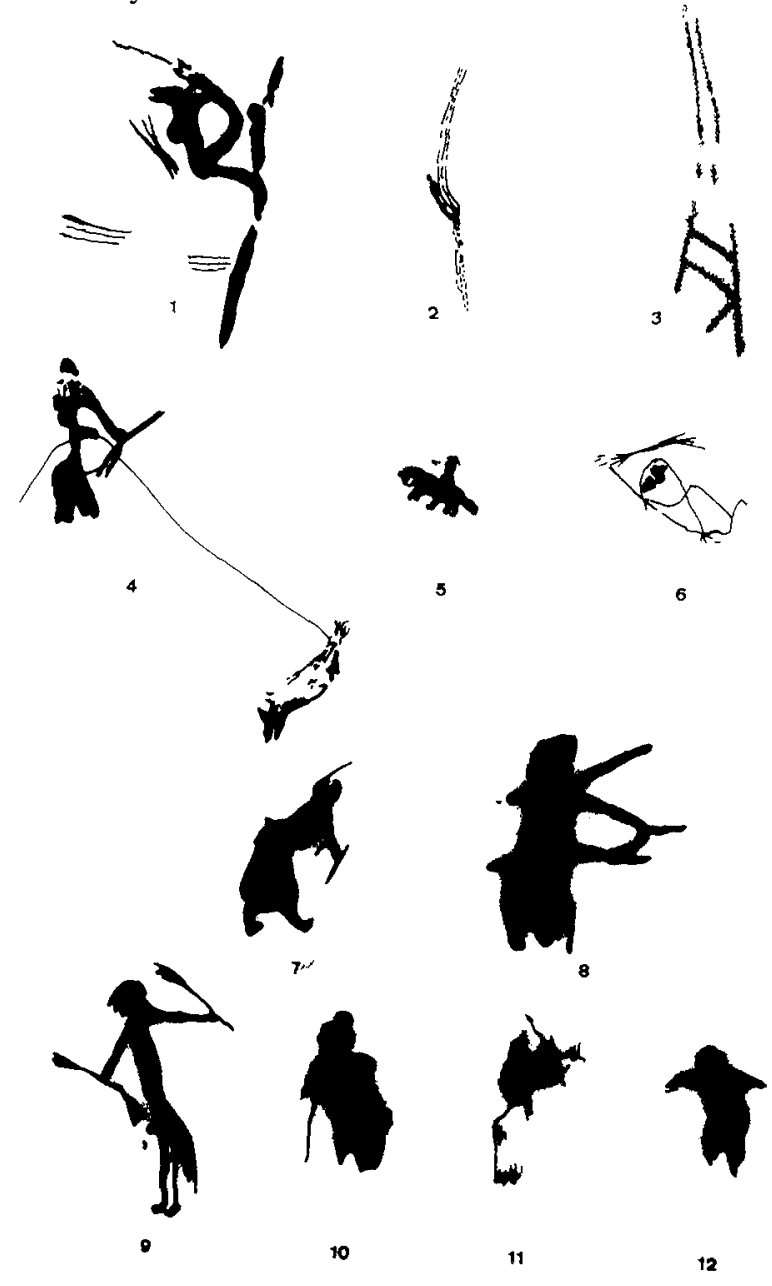

Fig. 16.-1, El Mas d'en Josep (VIÑAS, 1981); 2, La Araña (HERNÁNDEZ, 1924); 3-4, El Polvorín (VILASECA, 1947); 5, La Mola Remigia (RIPOLL, 1963); 6-7, El Ciervo (JORDÁ y ALCÁCER, 1951); 8, Cinto de la Ventana (JORDÁ y ALCÁCER, 1951); 9 y 12, Cueva Remigia (PORCAR, OBERMAIER y BREUIL, 1935); 10, EI Queso (BREUIL, SERRANO y CABRE, 1912); 11, La Vieja (CABRE, 1915). 
Probablemente estemos ante hachas en las figuraciones de un cazador de Cova del Rull (Fig. 17: 1) y de dos guerreros, uno de Cueva del Polvorín (VILASECA, 1947, lám. XXVIII, 2) y otro de Cueva de la Vieja (Fig. 17:2). Los paralelos figurativos los hallamos en las representaciones esquemáticas de Bacinete VII (ACOSTA, 1968, 155, f. 50: 9-12). Los paralelos muebles no faltan en las hachas y azuelas de piedra neolíticas, eneolíticas y de la Edad del Bronce. En este último período cultural son frecuentes las hachas de metal.

La presencia de bastones o varas (Fig. 17: 3; Fig. 15: 9), aunque no se trate de un arma propiamente dicha, está asociada a arcos, flechas y cestos en diversas panoplias de Cueva Remigia, Cingle de la Mola Remigia y Coves de la Saltadora. Según
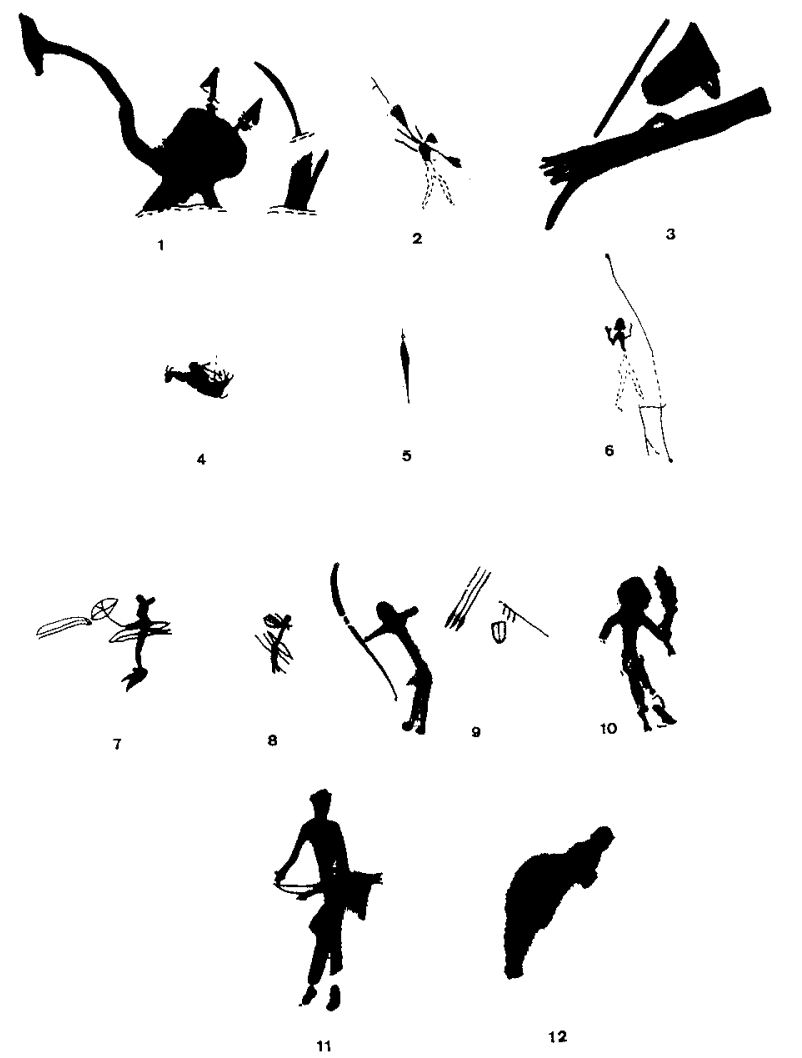

Fig. 17.-1, El Rull (OBERMAIER y WERNERT, 1919); 2, 6-8, La Vieja (BREUIL, SERRANO y CABRÉ, 1912; CABRÉ, 1915); 3, La Saltadora (OBERMAIER y WERNERT, 1919); 4 y 9, La Mola Remigia (RIPOLL, 1963); 5, El Polvorín (VILASECA, 1947); 10, Les Calçaes del Matà (VIÑAS, 1981); 11, El Ciervo (JORDÁ y ALCÁCER, 1951); 12, El Racó de Gasparó (PORCAR, 1965).
Esteve $(1974,16)$ servirían para remover y mezclar los componentes del veneno contenido en los recipientes.

Como armas punzantes calificamos una figuración de Cueva de la Vieja, relacionada con un guerrero (Fig. 17: 6) e interpretada como una lanza con punta foliácea (BREUIL, SERRANO y CABRÉ, 1912, 553), otra aislada de Cueva del Polvorín (Fig. 17: 5) considerada como espada (VILASECA, 1947, 29) y una última de Cingle de la Mola Remigia (Fig. 17: 4) como cuchillo (RIPOLL, $1963,28)$ o puñal (BLASCO, 1974, 50). La cronología relativa de la lanza sería la de las puntas de flecha foliáceas. La espada se asemeja al Tipo II de Almagro Gorbea $(1972,68)$ fechado entre 1100 y el $800 / 700$ a. C. y preferentemente representado en estelas decoradas del Suroeste.

Hay otros útiles de difícil interpretación que al estar asociados exclusivamente a cazadores, hemos supuesto que se trata de armas u objetos indeterminados con una función cinegética concreta. Figuran en Cingle de la Mola Remigia (Fig. 17:9), Coves de la Saltadora (Fig. 17:10) y Cueva de la Vieja (Fig. 17: 7-8).

- Grupo E.

Comprende dos objetos cuya función es difícilmente identificable. Uno de ellos figura en un cazador de Abrigo del Ciervo (Fig. 17: 11) como una mancha informe que, tal vez, represente una presa (¿gallinácea?) o una bolsa. El otro es sostenido por una figura femenina de Abrigo del Racó de Gasparó (Fig. 17: 12) y es interpretado por Porcar (1965, 176-177) como un pañuelo o abanico, quizá, de plumas.

\section{CONCLUSIONES}

A lo largo del presente artículo han sido expuestos los elementos etnográficos presentes en el Arte Rupestre Levantino, algunos de los cuales han podido ser datados relativamente por paralelos muebles y figurativos. De esta forma, y por orden cronológico, desde el Epipaleolítico se fecharían los arcos convexos y biconvexos; a partir del Neolítico, los brazaletes y ajorcas; desde los inicios del IV Milenio a. C., las puntas de flecha foliáceas y romboidales; a finales del Neolítico aparecen los paralelos de las puntas triangulares; durante el Eneolítico se inicia una actividad textil (lino y lana) y existe el trenzado del esparto, cuya aparición probablemente sea anterior, y ambas actividades 
datan de pantalones, las faldas, un carcaj y algunos cestos, en el supuesto que fuesen de estos materiales; también, en este período cultural se conocen las primeras diademas de metal, aunque pudieron ser anteriores si fuesen de fibras vegetales o tiras de cuero; durante el II Milenio a. C. hacen acto de presencia los tocados de plumas en el Mediterráneo Oriental, pero cabría la posibilidad de que fuera un adorno autóctono y más antiguo en la Península Ibérica. Todos estos datos nos remiten a una cronología relativa amplia.

En un intento de restringir dicha datación, hemos realizado asociaciones de adornos y útiles en una misma figura, que, por lo pronto, demuestran su convivencia en un momento sincrónico.

\subsection{GRUPO ASOCIATIVO DE LOS ADORNOS}

- Figuras masculinas.

- Fig. 18: 1: diadema-cintas en brazos y cintura-pantalones con picos laterales.

- Fig. 13: 5: diadema-cintas en la cintura-pantalones con picos laterales.

- Fig. 8: 2: diadema-cintas en la cintura-pantalones con bajos abullonados.

- Fig. 7: 3: diadema-cintas en brazos y cintura.

Se verifica que el denominador común de estas representaciones es llevar diademas y cintas en la cintura, y, por ello, deducimos que son contemporáneas. Ello nos induce a considerar que son, también, sus coetáneos, las cintas en los brazos, los pantalones con dos picos laterales y los de bajos abullonados.

Asimismo, pueden ser sincrónicas la Fig. 7: 2, con cintas en los brazos y en los pantalones, y la Fig. 18: 2, con diadema y pantalones con cintas.

De todo ello es deducible que fueron simultáneas las diademas, las cintas, en brazos y talle, y los tres tipos de pantalones.

Si tenemos en cuenta los pantalones con cintas, podemos dar un paso más. Éstos se asocian a brazaletes y ajorcas en las Fig. 7: 5 y Fig. 18: 3-4). Estos datos sugieren que en un momento dado se utilizaron tanto cintas como adornos cilíndricos en los brazos y las piernas.

- Figuras femeninas.

- Fig. 9: 5: diadema-cintas en los brazos-falda amplia.
- Fig. 9: 2: diadema-cintas en los brazos-falda triangular.

- Fig. 9: 3: diadema-cintas en los brazos-falda triangular.

Aquí, el denominador común es diademacintas en brazos y, por lo tanto, son coetáneas. Al asociarse con faldas amplias y triangulares (los dos casos con el convencionalismo de los dos picos laterales) se deduce su contemporaneidad. Las faldas triangulares, sin el convencionalismo, también coexisten con las faldas amplias, puesto que tienen en común las cintas en los brazos como se ve en la Fig. 9: 6 .

Otro dato añade la Fig. 9: 9, la cual lleva falda amplia y cintas en el talle. Como hemos visto, en las presentaciones masculinas, este adorno se asocia frecuentemente a las cintas en los brazos. Por consiguiente, sería contemporáneo, también, a éstas en las mujeres.

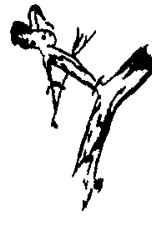

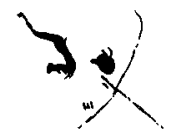

2
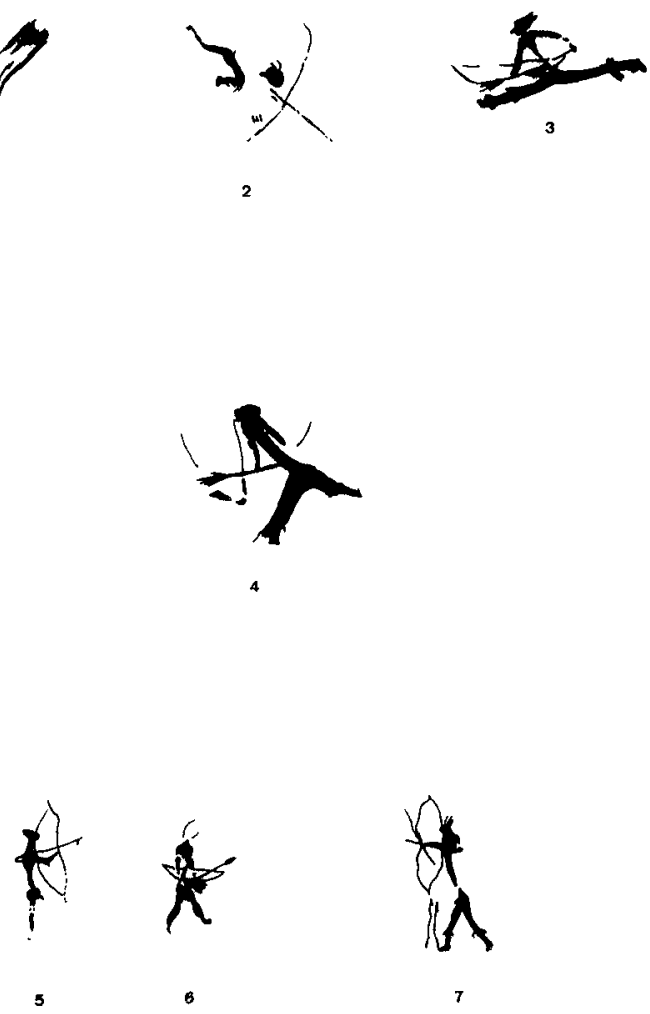

Fig. 18.-1, El Polvorín (VILASECA, 1947); 2, La Mola Remigia (RIPOLL, 1963); 3, Cueva Remigia (PORCAR, 1934); 4, Els Cavalls (OBERMAIER y WERNERT, 1919); 5-7, La Vieja (BREUIL, SERRANO y CABRE, 1912; CABRE, 1915). 
Todo ello implica que las diademas, las cintas, en brazos y cintura, y las fald as amplias y triangulares, coexistieron.

Otro dato interesante aporta la Fig. 9: 8. Asocia diadema-brazalete cilíndrico-falda triangular. Se observa que presenta dos elementos de la asociación planteada arriba. De esta manera, los brazaletes serían coetáneos de dicho grupo asociativo. Destaca el hecho de presentarse el mismo caso que en las figuras masculinas: en un momento dado fueron sincrónicos los brazaletes y las cintas en los brazos. Basándonos en la presencia de un brazalete en la Fig. 9: 7, que además asocia diadema-falda «de tubo», cabría pensar que estos dos elementos fueron coetáneos del grupo mencionado.

A modo de conclusión, se puede decir que en las figuras femeninas, las diademas, los brazaletes cilíndricos, las cintas, en brazos y talle, así como las tres formas de falda son contemporáneos.

Si analizamos las dos asociaciones obtenidas en ambos sexos, se constata que presentan como denominador común: las diademas, los brazaletes, las cintas en los brazos y en la cintura. Todos ellos coexistieron con los tres tipos de pantalones y las tres formas de faldas. En base a los brazaletes cilíndricos, el adorno con datación más segura, podemos afirmar que en un momento concreto, a partir del Neolítico, se dieron simultáneamente algunos adornos y las faldas y pantalones.

\subsection{GRUPO ASOCIATIVO DE LOS UTILES}

- Fig. 14: 4: arco-punta foliácea-carcaj.

- Fig. 7: 9: arco punta foliácea-bolsa.

- Fig. 15: 1: arco-punta foliácea-cesto.

El denominador común de estas figuras es llevar arco, flechas con punta foliácea y recipientes. Por consiguiente, fueron sincrónicos.

Si tenemos en cuenta que arcos-bolsas-carcajes se asocian a puntas con gancho (Fig. 14: 3 y 9), éstas serían también coetáneas del grupo asociativo formado arriba. Ello se ratifica por la relación existente entre puntas con gancho y puntas foliáceas observada en dos guerreros de una misma escena de Cueva de la Vieja (Fig. 18: 5-6).

Resumiendo, en un momento dado pudieron ser contemporáneos los arcos, las puntas foliáceas, las puntas con gancho y los tres tipos de recipientes. Esta coetaneidad se pudo dar a partir de los comienzos del IV Milenio a. C. No obstante, nos es imposible indicar, por ahora, en qué momento concreto se dio, pero lo cierto es que no fue anterior a dicho milenio.

\subsection{CONCLUSIONES FINALES}

Teniendo en cuenta los datos expuestos, es evidente que la cronología del grupo asociativo de los adornos habría de rebajarse hasta la fechación del grupo de los útiles, ya que los brazaletes (Fig. 7:5 y la escena bélica de Coves del Civil), las diademas con o sin plumas (Fig. 7: 9; Fig. 8: 10; Fig. 13:5) y las cintas en el talle (Fig. 7:9; Fig. 13:5) se asocian a puntas foliáceas.

En definitiva, la cronología relativa obtenida se basa eminentemente en las puntas foliáceas y, por tanto, la datación no puede remontarse más allá de los principios del IV Milenio a. C. Sin embargo, cabe indicar que esta datación es excesivamente generalizadora y poco concreta. Efectivamente, para establecer la fecha tope más alta de este milenio, nos basamos en la cronología dada al ejemplar de punta foliácea de sílex hallado en la capa 6. ${ }^{a}$ del Sector H-3 de Cova de l'Or (MARTÍ y otros, 1980, 297). Ante este caso único es muy peligroso aplicar su datación a las puntas foliáceas de nuestro arte. Por ello habría que darles una cronología más baja, a partir del Neolítico Final, momento en que las puntas foliáceas de sílex aparecen con más frecuencia, la cual irá aumentando durante el Eneolítico. Quizá, sería conveniente plantearse la posible relación entre la frecuencia de representación de puntas foliáceas en el Arte Rupestre Levantino y la frecuencia de aparición de semejantes puntas de sílex durante el Neolítico Final y Eneolítico. Esta cronología vendría corroborada por las puntas de flecha triangulares cuyos paralelos muebles, puntas con aletas y pedúnculo, tienen una fechación que, por el momento, no puede ser anterior al Neolítico Final.

A modo de conclusión, sólo se puede establecer que las figuras humanas de este arte prehistórico con representaciones de puntas de flecha foliáceas/romboidales y triangulares son fechables a partir de la transición del Neolítico al Eneolítico.

En el aspecto socio-cultural, se detecta la presencia de ciertos distintivos sociales y religiosos. Ahora bien, los distintivos actúan como tales en antropomorfos concretos, pero ello no quiere decir que tengan el mismo significado en otras figuras humanas. Los criterios determinantes de la presencia de un distintivo en una figuración humana son: 
que pertenezca a una escena de danza (con connotación religiosa), o que tengan un mayor tamaño o bien una situación destacada con respecto al resto de sus compañeras en otro tipo de escenas.

Al parecer, los distintivos más utilizados son los adornos, que podrían ser reflejo de un status social elevado o actuar como elementos religiosos. Algunos adornos, como las diademas solas, los tocados de plumas, los tocados altos y los penachos de plumas en la cintura, cumplen ambos cometidos actuando como distintivo social en escenas bélicas y cinegéticas, o como elemento religioso en escenas de danza.

Otros adornos parecen tener un significado estrictamente religioso, siendo el caso de las máscaras zoomorfas, relacionadas con ritos zoolátricos, y de dos ajorcas llevadas por personajes con posible carácter ritual-religioso.

Asimismo, la representación de arcos, flechas, palos de cavar, varas de plumas e idolillos, en algunas escenas de danza, indica probables ritos bélicos, cinegéticos, agrícolas y de fecundidad. Respecto a las panoplias aisladas, tal vez estemos ante un caso de simbolismo con valor mágico relacionado con la guerra y la caza.

A partir de lo expuesto, es deducible que los autores del Arte Levantino poseían una sociedad jerarquizada, cuyos jefes dirigían las batidas de caza y el combate organizado, y una religiosidad compleja con símbolos y ritos donde cabe destacar la intervención de la mujer, cuyo papel sobresaliente se comprueba por su excepcional representación siempre destacada.

\section{Alicante, Junio de 1985}

\section{BIBLIOGRAFIA}

\section{Abreviaturas}
A. P. L.
B. S. C. C.
Archivo de Prehistoria Levantina, Valencia.
C. I. P. P.
C. P. A. C.
J. A. U. A.

ACOSTA, P., 1968: La pintura rupestre esquemática en España. Salamanca.

ALFARO GINER, C., 1984: «Tejido y cestería en la Península Ibérica». Bibliotheca Praehistorica Hispana, XXI.

ALMAGRO BASCH, M., 1946: «Arte Levantino». Ars Hispaniae, I, 65-69.

- 1966: «Las estelas decoradas del Suroeste peninsular». Bibliotheca Praehistorita Hispana, VIII.

ALMAGRO GORBEA, M., 1972: «La espada de Guadalajara y sus paralelos peninsulares». Trabajos de Prehistoria, 29, 55-82.

- 1973: «Cascos del Bronce Final en la Península Ibérica». Trabajos de Prehistoria, 30, 349-362.

- 1974: «Orfebrería del Bronce Final en la Península Ibérica. El Tesoro de Abía de la Obispalía; la orfebrería Tipo Villena; los cuencos de Axtrokis. Trabajos de Prehistoria, 31, 39-100.

- 1977: «El Bronce Final y el Período Orientalizante en Extremadura». Bibliotheca Praehistorica Hispana, XIV.

APARICIO PÉREZ, J., 1980: «El Mesolítico». Nuestra Historia, I, 74-97.

APARICIO, J., MESEGUER, V. y RUBIO, F., 1982: El primer arte valenciano. II. El Arte Rupestre Levantino. Valencia.

ASQUERINO, M. D. y CENTRE D'ESTUDIS CONTESTANS 1980: «Nueva estación con pinturas rupestres en Benirrama (Vall de Gallinera, Alicante)». Altamira Symposium, 427-448.

BELTRÁN MARTÍNEZ, A., 1965: «El Racó de Gasparó y el Racó Molero (Ares del Maestre, Castellón)». Bulletin de la Société Préh istorique de l'Ariège, XX, 117-127.

- 1966: «Sobre representaciones femeninas en el Arte Rupestre Levantino». IX Congreso Nacional de Arqueología, 90-91.

- 1968: Arte Rupestre Levantino. Zaragoza.

- 1969: La Cueva de los Grajos y sus pinturas rupestres en Cieza (Murcia). Zaragoza.

- 1970: «Acerca de la cronología de la pintura rupestre levantina». Symposium Internationald'Art Préhistorique, 87-94.

- 1972: Los abrigos pintados de la Cañaíca del Calar y de la Fuente Sabuco, en El Sabinar, Murcia. Zaragoza.

- 1974: «Las pinturas prehistóricas de La Sarga (Alcoy), El Salt (Penáguila) y El Calvari (Bocairente)». Trabajos Varios del S. I. P., 47.

- 1979: Arte Rupestre Levantino. Adiciones 1968-1978. Zaragoza.

- 1982: De cazadores a pastores. El Arte Rupestre del Levante Español. Madrid.

BERNABÉU AUBÁN, J., 1982: «La evolución del Neolítico en el País Valenciano. Aportaciones al estudio de las culturas neolíticas en el extremo occidental del Mediterráneo». Revista del Instituto de Estudios Alicantinos, 37, 85-137.

BLASCO BOSQUED, M. C., 1974: «La caza en el Arte Rupestre del Levante Español». Cuadernos de Prehistoria y Arqueología de la Universidad Autónoma de Madrid, 1 , 29-55.

BOCQUET, A. et HOU'T, A., 1982: «La vie au Néolithique. Charavines, un village au bord d'un lac il y a 5.000 ans»». Histoire et Archéologie. Les Dossiers. 64. 
BREUIL, H., SERRANO, P. y CABRÉ, J., 1912: «Les abris del Bosque à Alpera (Albacete)». L'Anthropologie, XXIII, 529-562.

CABRÉ AGUILÓ, J., 1915: «El Arte Rupestre en España». C. I. P. P., 1 .

CAMPILLO, D. y VIÑAS, R., 1980: «Contribución a la Pa leopatología a través del Arte Rupestre». XXVII Congreso Internacional de Historia de la Medicina, 462-470.

CHAVES, F. y DE LA BANDERA, M. L., 1982: «Estela decorada de Montemolín (Marchena, Sevilla)». Archivo Español de Arqueología, 55, 137-148.

DAMS, L., 1984: Les peintures rupestres du Levant Espagnol. París.

DURÁN, A. y PALLARÉS, M., 1915-20: «Exploració arqueológica del Barranc de la Valltorta». Anuari de l'Institut d'Estudis Catalans, VI, 444-457.

ESTEVE GÁLVEZ, F., 1974: «Probable significación de unas pinturas rupestres del Maestrazgo». C. P. A. C., I, 9-18.

GÓMEZ BELLOT, S., 1971: «Nuevas pinturas rupestres en el término de Villafranca del Cid». I Congreso de Historia del País Valenciano, I, 185-188.

GÓNGORA, M. de, 1868: Antigüedades Prehistóricas de Andalucia. Madrid.

GONZÁLEZ PRATS, A., 1974: «El complejo rupestre del Riu de Montllor». Zephyrus, XXV, 259-275.

HERNÁNDEZ PACHECO, E., 1924: «Las pinturas prehistóricas de la Cueva de la Araña. Evolución del arte rupestre en España». C. I. P. P., 34.

HERNÁNDEZ PÉREZ, M. S., 1983: «Arte Rupestre». Alcoy, Prehistoria y Arqueología, 217-230.

HERNÁNDEZ, M. S. y CENTRE D'ESTUDIS CONTESTANS 1982: «Consideraciones sobre un nuevo tipo de arte rupestre prehistórico». Ars Praehistorica, I, 179-187.

- 1983: «Arte esquemático en el País Valenciano. Recientes aportaciones». Zephyrus, XXXVI, 63-78.

HUGOT, H.-J., 1974: Le Sahara avant le désert. Toulouse.

JORDÁ CERDÁ, F., 1966: «Notas para una revisión de la cronología del Arte Rupestre Levantino». Zephyrus, XVII, 47-76.

- 1970-71: «Los tocados de plumas en el Arte Rupestre Levantino». Zephyrus, XXI-XXII, 35-75.

- 1971: «Bastones de cavar, layas y arado en el Arte Rupestre Levantino». Munibe, XXIII, 241-248.

- 1974: «Formas de vida económica en el Arte Rupestre Levantino». Zephyrus, XXV, 209-223.

- 1975 a: «Las puntas de flecha en el Arte Levantino». XIII Congreso Nacional de Arqueología, 219-226.

- 1975 b: «La sociedad en el Arte Rupestre Levantino». Papeles del Laboratorio de Arqueología de Valencia, II, 159-184.

- 1975 c: «La Peña del Escrito (Villar del Humo, Cuenca) y el culto al toro». C. P. A. C., 2, 7-10.

- 1976: «¿Restos de un culto al toro en el Arte Levantino?». Zephyrus, XXVI-XXVII, 187-216.

- 1980: «Reflexiones en torno al Arte Levantino». Zephyrus, XXX-XXXI, 87-105.

- 1983: «El arte prehistórico de la región valenciana», I $J$. A. U.A. En prensa.

JORDÁ, F. y ALCÁCER, J., 1951: «Las pinturas rupestres de Dos Aguas (Valencia)». Trabajos Varios del S. I. P., 15.
KARAGEORGHIS, V. 1971: «Chipre». Archaelogia Mundi. Barcelona.

LECLANT, J. et HUARD, P., s. a.: La Culture des Chasseurs du Nil et du Sahara. Alger.

LEROI-GOURHAN, A., 1978: Préhistoire de l'Art Occidental. París.

LILLO CARPIO, P. y M., 1979: «Las pinturas de La Risca». Murcia, 15.

LULL, V., 1983: La «cultura» de El Algar. (Un modelo para el estudio de las formaciones económico-sociales prehistóricas). Barcelona.

MALUQUER DE MOTES, J., 1970: «Orfebrería prerromana en la Península Ibérica». Pyrenae, 6, 79-100.

MARCONELL, E., 1953: «Las pinturas rupestres de la Cueva Remigia». Noticiario Arqueológico Hispánico, 1, 1-3, 19-24.

MARTÍ OLIVER, B., 1983: «Los estudios del Neolítico en el País Valenciano y áreas próximas. Historia de la investigación, estado actual de los problemas y perspectivas». $I$ $J$. A. U. A. En prensa.

MARTÍ, B. y otros, 1980: «Cova de l'Or». Trabajos Varios del S. I. P., 65.

MELLAART, J., 1971: Çatal Hüyük, une des premières citées du Monde. Suisse.

MESADO OLIVER, N., 1981: «La Cova del Mas d'en Llorenç y el arte prehistórico del Barranco de la Gasulla». A. P. L., XVI, 281-306.

MONTANDON, G., 1934: L'Ologénèse Culturelle. Traité d'Ethnologie Cyclo-culturelle et d'Ergologie Systématique. París.

MONZONIS, F., y VIÑAS, R., 1981: «Cinco nuevos abrigos con arte rupestre en la zona de Bicorp (Valencia)». Altamira Symposium, 397-410.

MORGAN, J. de, 1921: L'Humanité Préhistorique. Esquisse de Préhistoire générale. París.

MUÑOZ AMILIBIA, A. M., 1982: «La Edad del Bronce en el Sureste de España». XVI Congreso Nacional de Arqueología. Ponencia.

- 1983: «El Eneolítico en el País Valenciano». I J. A. U. A. En prensa.

NAVARRO MEDEROS, J. F., 1983: «La explotación del territorio en la Península Ibérica durante el Bronce Pleno. Aproximación a su estudio». Tabona, IV, 29-93.

OBERMAIER, H., y WERNERT, P., 1919: «Las pinturas rupestres del Barranco de la Valltorta (Castellón)». C. I. P. P. 23.

PARROT, A., 1981: Sumer. Madrid.

PERICOT GARCÍA, L., 1974: «La vida social de los cazadores paleolíticos españoles a través del Arte Levantino». Miscelánea Arqueológica, II, 173-195.

PLA BALLESTER, E., 1972: «Aportaciones al conocimiento de la agricultura antigua en la región valenciana». Omaggio a Fernand Benoit, II, 319-354.

PORCAR RIPOLLÉS, J. B., 1932: «La pintura rupestre de La Joquera». B. S. C. C., XIII, 228-236.

- 1934: «Pinturas rupestres al Barranc de la Gasulla». B. S. C. C., XV, 343-347.

- 1943: «Sobre las pinturas rupestres de Ares del Maestre». B. S. C. C., XVIII, 15-16.

- 1945: «Interpretaciones sobre el arte rupestre». A. P. L., II, 31-37. 
- 1953: «Las pinturas rupestres del Barranco de Les Dogues». A. P. L., IV, 75-80.

- 1964: «Impresiones sobre el arte rupestre existente en el Maestrazgo». Prehistoric Art of the Westem Mediterranean and the Sahara, 159-164.

- 1965: «Las pinturas del Racó de Gasparó». B. S. C. C., XLI, 176-179.

PORCAR, J. B., OBERMAIER, H., y BREUIL, H., 1935: «Excavaciones en la Cueva Remigia (Castellón)». Memorias de la Junta Superior de Excavaciones Arqueológicas, 136.

RIPOLL PERELLÓ, E., 1961: Los abrigos pintados de los alrededores de Santolea (Teruel). Barcelona.

- 1962: «Representación de un jinete en las pinturas rupestres del Cingle de la Gasulla (Castellón)». Zephyrus, XIII, 91-93.

- 1963: Pinturas rupestres de la Gasulla (Castellón). Barcelona.

- 1968: «Cuestiones en tomo a la cronología del arte rupestre postpaleolítico en la Península lbérica». Simposio de Arte Rupestre en Barcelona, 165-192.

- 1970: «Notícia sobre l'estudi de les pintures rupestres de "La Saliadora" (Barranc de la Valltorta, Castelló)». Estudios dedicados a Agustín Durán i Sampere, III, 9-24.

ROZOY, J.-G., 1978: Les derniers chasseurs. L'Epipaleolithi- que en France et en Belgique. Essai de Synthèse. Charleville.

SOLER GARCÍA, J. M., 1965: «El Tesoro de Villena (Alicante)》. Excavaciones Arqueológicas en España, 36.

VANDIER, J., 1952: Manuel d'Archéologie Egyptienne, I, 1. Paris.

VARELA, M. y PINHO, J., 1977: «Las estelas decoradas do Pomar (Beja, Portugal). Estudio comparado». Trabajos de Prehistoria, 34, 165-214.

VILASECA ANGUERA, S., 1947: «Las pinturas rupestres de la Cueva del Polvorín, Puebla de Benifazá, Castellón». Informes y Memorias de la Comisión General de Excavaciones Arqueológicas, 17.

VILLAVERDE, V., PEÑA, J. L. y BERNABEU, J., 1981: «Dos estaciones de arte rupestre levantino en Millares». A. P. L., XVI, 307-318.

VIÑAS VALLVERDÚ, R., 1979-80: «Figuras inéditas del Barranco de la Valltorta». Ampurias, 41-42, 1-34.

- 1981: «Arte rupestre. La Valltorta y su conjunto rupestre». La Valltorta. Castellón.

VIÑAS, R., SARRIÀ, E., y MONZONIS, F., 1979: «Nuevas manifestaciones de arte rupestre en el Maestrazgo (Castellón de la Plana)». C. P. A. C., 6, 99-120.

WERNERT, P., 1917: «Nuevos datos etnográficos para la cronología del arte rupestre de estilo naturalista del Oriente de España». C. I. P. P., nota n. ${ }^{\circ} 13$. 